NBER WORKING PAPER SERIES

\title{
INDIVIDUAL PREFERENCES, MONETARY GAMBLES AND THE EQUITY PREMIUM
}

Nicholas Barberis

Ming Huang

Richard Thaler

Working Paper 9997

http://www.nber.org/papers/w9997

\author{
NATIONAL BUREAU OF ECONOMIC RESEARCH \\ 1050 Massachusetts Avenue \\ Cambridge, MA 02138 \\ September 2003
}

We thank John Campbell, Darrell Duffie, Larry Epstein, Faruk Gul, John Heaton, Daniel Kahneman, Terry Odean, Mark Rubinstein, Bill Sharpe, Jeff Zweibel and seminar participants at INSEAD, Princeton University, Stanford University, UC Berkeley, the University of Chicago and the NBER for helpful comments. The views expressed herein are those of the authors and are not necessarily those of the National Bureau of Economic Research.

(C2003 by Nicholas Barberis, Ming Huang, and Richard Thaler. All rights reserved. Short sections of text, not to exceed two paragraphs, may be quoted without explicit permission provided that full credit, including (C) notice, is given to the source. 
Individual Preferences, Monetary Gambles and the Equity Premium

Nicholas Barberis, Ming Huang, and Richard Thaler

NBER Working Paper No. 9997

September 2003

JEL No. D1, D8, G11, G12

\section{ABSTRACT}

We argue that narrow framing, whereby an agent who is offered a new gamble evaluates that gamble in isolation, separately from other risks she already faces, may be a more important feature of decision-making under risk than previously realized. To demonstrate this, we present evidence on typical attitudes to independent monetary gambles with both large and small stakes and show that across a wide range of utility functions, including all expected utility and many non-expected utility specifications, the only ones that can easily capture these attitudes are precisely those exhibiting narrow framing. Our analysis also makes predictions about the kinds of preferences that might be able to address the stock market participation and equity premium puzzles. We illustrate these predictions in simple portfolio choice and equilibrium settings.

Nicholas Barberis

Graduate School of Business

University of Chicago

1101 East $58^{\text {th }}$ Street

Chicago, IL 60637

and NBER

nick.barberis@gsb.uchicago.edu

Richard Thaler

Graduate School of Business

University of Chicago

1101 East $58^{\text {th }}$ Street

Chicago, IL 60637

and NBER

richard.thaler@gsb.uchicago.edu
Ming Huang

Stanford University

mhuang@leland.stanford.edu 


\section{Introduction}

Economists, and financial economists in particular, have long been interested in how people evaluate risks of different kinds. In this paper, we try to shed new light on this topic. Specifically, we argue that a feature known as narrow framing may play a more important role in decision-making under risk than previously realized.

In traditional models that define utility over total wealth or consumption, an agent who is offered a new gamble evaluates that gamble by merging it with the other risks she already faces and checking whether the combination is attractive. Narrow framing, by contrast, occurs when an agent who is offered a new gamble evaluates that gamble to some extent in isolation, separately from her other risks. More formally, she derives utility directly from the outcome of the gamble, and not just indirectly from its contribution to total wealth. Equivalently, her utility function depends on the outcome of the new gamble over and above what that outcome means for her total wealth or consumption risk.

Our starting point is attitudes to the simplest imaginable form of risk: independent monetary gambles with just two equiprobable outcomes, a gain and a loss, of small to moderate size. The accumulated evidence from years of experimental work suggests that people are strongly averse to such gambles when the gain is much less than twice the size of the loss. To confirm this result once again, we conduct our own experiments with several groups of subjects, including one group of very wealthy individuals, and find that the majority do indeed reject a 50:50 bet offering, for example, a $\$ 550$ gain against a $\$ 500$ loss.

We then ask what kinds of intertemporal utility functions can explain this aversion to small-scale risk, and at the same time, make sensible predictions about attitudes to largescale gambles: for example, that the individual would accept a clearly attractive large-scale gamble such as a $50: 50$ bet to win $\$ 20$ million or lose $\$ 10,000$.

While the observations we are trying to explain seem very intuitive, we find that a surprisingly wide range of utility functions, covering all expected utility and many nonexpected utility specifications, have great difficulty capturing them. Among utility functions used by financial economists, the only ones that can address these observations with any degree of satisfaction are precisely those exhibiting narrow framing, as well another feature known as first-order risk aversion. First-order risk aversion means that a utility function is locally risk averse, unlike many standard preferences that are smooth and therefore locally risk-neutral. Loss aversion, whereby the agent's utility function is kinked at the current wealth level, is a simple example of first-order risk aversion.

To see why these two features are necessary, consider first a utility function without first-order risk aversion, in other words, one which is locally smooth. Since the agent is locally risk-neutral, she will normally be very happy to accept a small, actuarially attractive 
gamble like the $550 / 500$ bet. $^{1}$ To make her reject it, we need to generate very high local curvature, which in turn means choosing very extreme parameters. However, such parameters almost always also imply very high global risk aversion, thereby making the individual reject apparently attractive larger-scale gambles like the 20 million/10,000 bet. To avoid such counterfactual predictions, we need utility functions that are locally risk averse, not locally risk-neutral; in other words, utility functions exhibiting first-order risk aversion.

This argument for first-order risk aversion has already appeared in various guises in the literature (Epstein and Zin 1990, Rabin 2000). Our contribution on this specific point is simply to check whether results known to hold in static settings also extend to intertemporal ones. Our principal contribution, however, is a novel argument showing that even utility functions with first-order risk aversion have difficulty explaining attitudes to large and smallscale risks at the same time and that in general, narrow framing is also needed.

The intuition for this result is straightforward. Suppose that an investor with first-order risk aversion, but who does not engage in narrow framing, is offered a small, actuarially attractive and independent gamble to be resolved at some point in the future: the 550/500 bet, say. Now also make the reasonable assumption that the investor faces some pre-existing risk, such as labor income risk or house price risk. In the absence of narrow framing, the investor must evaluate the new gamble by merging it with her pre-existing risk and checking if the combination is attractive. It turns out that the combination is almost always attractive: since the new gamble is independent of the agent's other risks, it brings her useful diversification benefits, which, even though first-order risk averse, she can still enjoy. The only way to make the agent reject the gamble is, once again, to choose extreme parameter values. However, these parameters will again imply, counterfactually, the rejection of clearly attractive gambles with larger stakes, such as the 20 million/10, 000 bet.

In order to explain the commonly observed aversion to the $550 / 500$ bet, then, it must be that the investor does not fully merge it with pre-existing risks, but that to some extent, she evaluates it in isolation; in other words, she must frame the gamble narrowly. Using a recently developed preference specification that allows for both first-order risk aversion and narrow framing, we confirm that such utility functions can indeed easily explain aversion to the 550/500 bet, while also making sensible predictions about attitudes to large-scale risks: if the agent's first-order risk aversion is focused specifically on the 550/500 bet rather than just on her overall wealth risk, she will be reluctant to take the gamble.

Our analysis of independent monetary gambles has useful implications for financial markets and in particular, for understanding the stock market participation and equity premium puzzles. Consider first the participation puzzle: the fact that even though stocks have a high mean return, many people appear reluctant to allocate any money to them (Mankiw and

\footnotetext{
${ }^{1}$ We use the notation $g / l$ to refer to a $50: 50$ bet offering a gain of $\$ g$ against a loss of $\$ l$.
} 
Zeldes 1991, Haliassos and Bertaut 1995). What kinds of preferences might most easily generate such non-participation?

Previous research has found that for most households, stock market risk has a correlation close to zero with other important risks, such as labor income risk, proprietary income risk and house price risk (Heaton and Lucas, 2000). Asking what kinds of preferences can explain non-participation therefore reduces to asking what kinds of preferences can explain people's refusal to add even a small amount of a relatively uncorrelated risk - stock market risk - to their other risks.

Our earlier analysis is well-suited for answering this question. There, we saw that the easiest way to explain rejection of a small, uncorrelated gamble is to use preferences with first-order risk aversion and that allow for the narrow framing of the gamble. A simple way of explaining the rejection of a small position in the stock market is therefore to use preferences with first-order risk aversion and that allow for the narrow framing of stocks in other words, the evaluation of stock market risk in isolation, to some extent.

In a simple portfolio choice setting, we confirm this prediction, as well another prediction of our earlier analysis: that preferences without narrow framing will have a harder time explaining non-participation, even if they exhibit first-order risk aversion. In the absence of narrow framing, the investor must evaluate stocks by merging them with her other risks and checking if the combination is attractive. Since stocks are a relatively uncorrelated risk, a small equity position brings useful diversification benefits which the investor generally does find attractive, even if first-order risk averse. By having the investor evaluate stocks in isolation - by focusing her first-order risk aversion specifically on stocks rather than just on her overall wealth risk - we get around this difficulty and can more easily generate nonparticipation.

Our results on monetary gambles also shed light on what kinds of preferences might be able, in a representative agent equilibrium, to generate a large equity premium. We argue that in many representative agent economies, the stock market is a relatively uncorrelated and relatively small risk. In such economies, then, preferences with first-order risk aversion and that allow for the narrow framing of stocks should easily generate aversion to equity risk, and thereby also a large premium for holding that risk. We confirm this, and also show that the narrow framing ingredient is again important. Preferences with first-order risk aversion alone do not generate as large a premium: the representative agent is then much more willing to hold stocks, as merging them with her pre-existing risks is diversifying.

Our paper builds on earlier work investigating what kinds of preferences can simultaneously explain attitudes to both small and large-scale risks. Kandel and Stambaugh (1991) point out that power utility functions have trouble doing so, while Rabin (2000) shows that the difficulty extends to all one-period expected utility functions defined over wealth. The 
main contribution of our research is to show that the problem extends more broadly, to a much wider range of preferences, and indeed that it is almost impossible to explain attitudes to both large and small-scale risks without appealing to narrow framing.

While the term "narrow framing" was first used by Kahneman and Lovallo (1993), the more general concept of "decision framing" was introduced much earlier by Tversky and Kahneman (1981). There are already several cleverly-designed laboratory demonstrations of narrow framing available in the literature. ${ }^{2}$ Our paper shows that a more basic piece of evidence on attitudes to risk, not normally associated with narrow framing, should most probably also be thought of in these terms. Moreover, while existing demonstrations of narrow framing do not always have obvious counterparts in the everyday risks people face, the simple risks we consider $d o$ - not least in stock market risk - making our results applicable in a variety of contexts.

In Section 2, we discuss typical attitudes to simple monetary gambles and introduce various classes of utility functions whose ability to match those attitudes we are interested in. In Section 3, we show that without first-order risk aversion, it is hard to match these attitudes. In Section 4, we present our main result: that even first-order risk aversion is not enough and that narrow framing is required as well. In Section 5, we apply our analysis to understanding what kinds of utility functions might be able to resolve the stock market participation and equity premium puzzles. Section 6 discusses various interpretations of narrow framing and Section 7 concludes.

\section{Attitudes to Monetary Gambles}

Consider the independent, small-stakes gamble ${ }^{3}$

$$
G_{S}=\left(550, \frac{1}{2} ;-500, \frac{1}{2}\right)
$$

to be read as "gain $\$ 550$ with probability $\frac{1}{2}$ and lose $\$ 500$ with probability $\frac{1}{2}$." It is the premise of this paper that people find this gamble unattractive. We base this premise on numerous experimental studies, including the work of Kahneman and Tversky (1979) and Tversky and Kahneman (1992), showing that people typically reject gambles with two equiprobable outcomes of small to moderate size when the potential gain is less than twice the potential loss.

\footnotetext{
${ }^{2}$ Read, Loewenstein and Rabin (1999) provide a broad survey of many instances of narrow framing, including those documented by Tversky and Kahneman (1981), Tversky and Kahneman (1986), Redelmeier and Tversky (1992), Kahneman and Lovallo (1993), Gneezy and Potters (1997) and Thaler et al. (1997).

${ }^{3}$ The "S" subscript in $G_{S}$ stands for Small stakes.
} 
To confirm that this premise holds even for people with above average income prospects, we conducted some additional experiments of our own with four different groups of subjects, including one group of very wealthy individuals. The four groups are: (i) 68 part-time MBA students at the University of Chicago, most of whom are fully employed; (ii) 30 financial advisors at a mid-size U.S. brokerage firm; (iii) 19 Chief Investment Officers and Directors of quantitative equity research at large asset management firms; and (iv) 34 clients of the private wealth management division of a U.S. bank. The median wealth of subjects in this last group exceeds $\$ 10$ million.

We asked each group for their reaction to $G_{S}$ and other similar gambles. We did not play the gambles for real money but simply asked subjects to think hard about how they would choose. Table 1 presents the results. It confirms that for a majority of subjects in all four groups, $G_{S}$ was indeed unattractive. While the wealthiest group, group (iv), did accept $G_{S}$ more often than other groups, the majority of subjects in even that group continued to reject it.

Economists are often skeptical of answers to hypothetical questions. In this context though, if there is a bias, it is that hypothetical questions understate the risk aversion observed when playing the gambles for real money. To illustrate this, we conducted one real-money experiment on a fifth group of subjects, group (v), consisting of 41 part-time MBA students at the University of Chicago. They were asked whether they would play a 110/100 bet for real money. To be specific, they were told that if they wanted to accept this gamble, they should indicate so on the experimental form, and then come to class the following week with the $\$ 100$ they would need in case they lost. They were informed that if they won, they would be paid immediately in cash. Of the 41 students that participated, only 4 , or $10 \%$, were willing to accept the gamble. Given that $24 \%$ of the MBA students in group (i) were willing to accept a hypothetical version of this gamble, it appears that playing for real money only makes bets like $G_{S}$ even more unattractive. ${ }^{4}$

Some authors have argued that the aversion to small losses that we and others document in experimental settings is very consistent with field evidence on attitudes to small risks. Rabin and Thaler (2001) argue that the premia consumers pay for telephone wiring insurance, reported by Cicchetti and Dubin (1994), are so high as to suggest substantial aversion to even small risks. Grgeta and Thaler (2003) reach the same conclusion after observing unusually

\footnotetext{
${ }^{4}$ We follow the earlier literature in interpreting the rejection of $G_{S}$ as a statement about risk aversion. One alternative view is that the rejection is due to transaction costs: such costs might be incurred if a liquidity-constrained investor needs to sell illiquid assets to finance a loss (Chetty, 2002). It is hard to argue that such a mechanism is at work for groups (iii) and (iv) in Table 1, though, as the potential losses are surely tiny compared to these individuals' liquid wealth. Nor is suspicion a plausible explanation for the rejection of $G_{S}$ : fear that even in event of a win, the experimenter will refuse to pay out. Suspicion tends to arise only for offers that are "too good to be true," which is hardly the case for a gamble with a gain/loss ratio of 1.1. Moreover, the experimenters are known to all the subjects, making it easy to track them down in case of default.
} 
low choices of deductibles in data on automobile collision insurance. Any results we derive about what is driving the rejection of small gambles in experimental settings may also be relevant for understanding such evidence from the field..$^{5} 6$

In Sections 3 and 4, we investigate what kinds of utility functions can capture the commonly observed aversion to gambles like $G_{S}$. Of course, many utility functions can explain this evidence simply by assuming sufficiently high risk aversion. To provide a reasonable upper bound on individual risk aversion, we introduce a new gamble involving larger stakes, ${ }^{7}$

$$
G_{L}=\left(20,000,000, \frac{1}{2} ;-10,000, \frac{1}{2}\right) .
$$

It is the premise of this paper that this bet is typically accepted. Indeed, when presented with this bet, the vast majority of subjects in groups (i) to (iv) were indeed willing to accept it.

In summary, then, we are interested in knowing what kinds of preference specifications can explain both that " $G_{S}$ is rejected" and that " $G_{L}$ is accepted." We do not insist that utility functions be able to explain these observations at all wealth levels. Rather, we make the weaker demand that they explain them over a reasonable range of wealth levels - neither too high nor too low. To be precise, we check whether they can explain:

I. $G_{S}$ is rejected for wealth levels $W \leq \$ 1,000,000$

II. $G_{L}$ is accepted for wealth levels $W \geq \$ 100,000$.

In our view, observations I and II represent a relatively conservative reading of the available evidence. Experiments conducted by us and by other researchers suggest that people turn down $G_{S}$ even at a wealth level of $\$ 10$ million and that they turn down small gambles with substantially higher ratios of gain to loss. Furthermore, while some researchers

\footnotetext{
${ }^{5}$ We also note, however, that the field evidence has proven controversial: Palacios-Huerta, Serrano and Vollij (2003) point out that some field studies of attitudes to small risks report relatively low risk aversion - lower than that implied by the rejection of $G_{S}$ at a wealth level of $\$ 1$ million, say. However, the studies they cite tend to use monthly income, or even smaller quantities, in place of wealth when computing risk aversion. Using a more realistic measure of the individual's total wealth in these calculations brings the risk aversion implied by the field evidence closer to that implied by the rejection of $G_{S}$.

${ }^{6}$ The evidence of aversion to gambles like $G_{S}$ is in no way inconsistent with risk-taking behavior like casino gambling or the buying of lottery tickets. Lottery tickets are quite different from $G_{S}$, in that they involve a tiny probability of substantial gain. Kahneman and Tversky (1979) argue that people overweight small probabilities - a feature which indeed leads to risk-seeking over low probability gains, but which is not relevant for the equiprobable outcomes of $G_{S}$. Gambling is also a special phenomenon, in that people would never accept the terms of trade offered at a casino if they were offered by their bank, say. It must be that amidst the flashing lights and hubbub of a casino, people either misestimate their chance of winning or else receive utility from the gambling activity itself.

${ }^{7}$ The $L$ subscript on $G_{L}$ stands for Large stakes.
} 
suggest that a power utility function $\frac{W^{1-\gamma}}{1-\gamma}$ with a $\gamma$ of 2 adequately describes attitudes to large-scale, independent monetary gambles - see Kandel and Stambaugh (1991), for example - observation II is weak enough a restriction on such attitudes that it can be satisfied by a $\gamma$ as high as 7. Of course, strengthening our starting premises I and II would only make our arguments in later sections hold with even greater force.

We emphasize again that the challenge itself - explaining observations I and II at the same time - is not new. A long line of researchers, including Epstein and Zin (1990), Kandel and Stambaugh (1991), Cochrane (1997) and Rabin (2000) have posited these or similar attitudes to small and large-scale risks, and then asked what kinds of preferences might capture them. Our goal is to make new progress in answering this question.

When we check utility functions' ability to explain observations I and II, it can make a difference, for certain utility specifications, whether the gambles are "immediate" or "delayed." A gamble is immediate if its uncertainty is resolved at once, before any further consumption decisions are made. A delayed gamble, on the other hand, might be played out as follows: in the case of $G_{S}$, the subject is told that at some point in the next few months, she will be contacted and informed either that she has just won $\$ 550$ or that she has lost $\$ 500$, the two outcomes being equally probable and independent of other risks.

Although certain utility functions can predict different attitudes to immediate and delayed gambles, we think that in reality, people do not treat the two kinds of bets very differently. To test this intuition, we asked the MBA students in group (v) one additional hypothetical question: whether they would accept a 110/100 gamble if it were played out on a day picked at random during 2003. (The survey was conducted in October 2002.) The subjects largely shared our intuition: only 9 of the 41 subjects, or $22 \%$, were willing to accept this delayed gamble, a fraction very similar to the fraction of MBA students in group (i) willing to accept the immediate $110 / 100$ bet, namely $24 \%$.

In view of this evidence, we insist that the preference specifications we consider be able to capture observations I and II in both cases, immediate and delayed. In our initial analysis, we will only need to work with the computationally simpler immediate gambles: it turns out that many classes of utility functions have trouble explaining attitudes even to those. In cases where utility functions are able to capture attitudes to immediate gambles, we challenge them with delayed gambles as well. ${ }^{8}$

\footnotetext{
${ }^{8}$ To make some of our later arguments completely precise, we will make brief use of a third version of the 550/500 gamble, a "continuously resolved" version. In this case, just as with the delayed gamble, the subject is told that at some point in the future, she will win either $\$ 550$ or lose $\$ 500$, the two outcomes being equally likely and independent of other risks. The difference between this and the delayed gamble, however, is that every day from now until the final payout, the subject is told the updated probability of eventually winning $\$ 550$. In other words, while the delayed gamble's uncertainty is resolved at a single instant in the future, the continuously resolved gamble's uncertainty unfolds gradually over time. We have found people to be as averse to this third version of the 550/500 gamble as to the immediate and delayed versions.
} 


\subsection{Utility Functions}

We now introduce the different classes of utility functions whose ability to capture observations I and II we are interested in. Throughout the paper, we work with intertemporal preferences, not static ones. There are two reasons for this. First, an important part of our analysis deals with delayed gambles, whose uncertainty is only fully resolved after today's consumption is set, and which must therefore be analyzed in a multiperiod framework. Second, the reason people derive utility from wealth in the first place is the future consumption stream that wealth is able to finance. A "first principles" approach therefore suggests starting with intertemporal utility defined over consumption, rather than static utility defined over wealth. The extra effort is worthwhile because, as we will see, results that hold in a static context do not necessarily hold in an intertemporal setting, at least not without stronger assumptions.

We consider the following preferences, listed along with the abbreviations used to refer to them. Our list is not intended to be an exhaustive one; we focus only on classes of utility functions commonly used by financial economists:

[EU]: Expected utility preferences

Non-expected utility preferences:

[R-EU]: Recursive utility with EU certainty equivalent

[R-SORA]: Recursive utility with non-EU, second-order risk averse certainty equivalent [R-FORA]: Recursive utility with non-EU, first-order risk averse certainty equivalent

Expected utility preferences are familiar enough. What about non-expected utility specifications? In an intertemporal setting, non-expected utility is typically implemented via a recursive structure in which time $t$ utility, $V_{t}$, is defined through

$$
V_{t}=W\left(C_{t}, \mu\left(\widetilde{V}_{t+1} \mid I_{t}\right)\right)
$$

Here $\mu\left(\tilde{V}_{t+1} \mid I_{t}\right)$ is the certainty equivalent of the distribution of future utility $\tilde{V}_{t+1}$ conditional on time $t$ information, and $W$ is an aggregator function that aggregates current consumption $C_{t}$ with the certainty equivalent of future utility to give current utility. Epstein and Zin (1989) present a detailed analysis of such preferences.

We consider three kinds of recursive utility. They differ in the properties they impose on $\mu$. One property that plays an important role is the order of risk aversion built into $\mu$, and in particular whether $\mu$ exhibits "second-order" or "first-order" risk aversion, terms originally coined by Segal and Spivak (1990). An agent's utility function exhibits secondorder risk aversion if it predicts risk-neutrality for infinitesimal risks. In simple terms, such 
utility functions are smooth. First-order risk averse utility functions, on the other hand, are preferences where the investor is risk averse even over infinitesimal bets. A simple example of a utility function with this property is one exhibiting loss aversion, or a kink at the agent's current wealth. ${ }^{9}$

Utility functions in the expected utility class can generically only exhibit second-order risk aversion: an increasing, concave utility function can only have a kink at a countable number of points. Non-expected utility functions, on the other hand, can exhibit either second-order or first-order risk aversion, and it is important to consider these cases separately.

We now describe the three kinds of recursive utility in more detail. First, we look at recursive preferences in which the certainty equivalent function $\mu$ has the expected utility form

$$
\mu(\widetilde{X})=h^{-1} E h(\widetilde{X}),
$$

a class we call R-EU. Most implementations of recursive utility in financial economics, including those of Campbell (1996) and Campbell and Viceira (1999), are of the R-EU form. Researchers use these preferences primarily because they offer a simple way of separating risk aversion and intertemporal elasticity of substitution, something which cannot be done satisfactorily within the expected utility class. ${ }^{10}$

Next, we consider recursive utility in which $\mu$ is in the non-expected utility class but still exhibits second-order risk aversion, the R-SORA category; such preferences have been studied by Epstein and Zin (2001), among others. Finally, we look at recursive utility in which $\mu$ is again non-expected utility, but now exhibits first-order risk aversion. Implementations of such R-FORA preferences include Epstein and Zin (1990), Bekaert, Hodrick and Marshall (1997) and Ang, Bekaert and Liu (2002).

In Section 3, we argue that utility functions with second-order risk aversion - in other words, the EU, R-EU and R-SORA classes - have difficulty explaining the attitudes to monetary gambles listed in observations I and II, thereby suggesting that preferences with first-order risk aversion - the R-FORA class - might do better. While the results in this section are an important building block for our later analysis, they are also less novel. We therefore simply state them with little fanfare and keep illustrative examples to a minimum.

In Section 4, we present our main result, namely that even utility functions with firstorder risk aversion are ultimately unable to explain observations I and II in a satisfactory way, and that a second ingredient, narrow framing, is also required.

\footnotetext{
${ }^{9}$ More formally, second-order risk aversion implies that the premium paid to avoid an actuarially fair gamble $k \widetilde{\varepsilon}$ is, as $k \rightarrow 0$, proportional to $k^{2}$. Under first-order risk aversion, the premium is proportional to $k$.

${ }^{10}$ Note that even though, for R-EU preferences, $\mu$ is in the expected utility class, intertemporal utility $V_{t}$ is still non-expected utility.
} 


\section{The Importance of First-order Risk Aversion}

\section{$3.1 \quad$ Expected Utility}

As is standard in an intertemporal setting, the expected utility preferences we consider are defined over a consumption stream,

$$
E\left(U\left(C_{0}, \widetilde{C}_{1}, \ldots, \widetilde{C}_{T}\right)\right),
$$

with $U$ increasing and concave in each argument. In the case where future utility does not depend on past consumption, mild conditions imply that optimizing expected utility over consumption leads to an indirect value function of the form

$$
J\left(W_{t} ; I_{t}\right)=\max E_{t}\left(U\left(C_{t}, \widetilde{C}_{t+1}, \ldots, \widetilde{C}_{T}\right)\right),
$$

where $I_{t}$ denotes information available about the state of the economy at time $t$. When future utility does depend on past consumption, the indirect value function becomes

$$
J\left(W_{t} ; I_{t}, C_{-t}\right)=\max E_{t}\left(U\left(C_{0}, \ldots, C_{t}, \widetilde{C}_{t+1}, \ldots, \widetilde{C}_{T}\right)\right),
$$

where $C_{-t} \equiv\left\{C_{0}, C_{1}, \cdots, C_{t-1}\right\}$ denotes the individual's past consumption history.

We now ask whether the expected utility preferences in (3) can explain the attitudes

to risk listed in observations I and II. The following proposition establishes that no utility function in this class can do so. Part (a) of the proposition addresses the preferences in (4), while part (b) addresses the preferences in (5), for which a stronger assumption is required to deliver the result.

Proposition 1.

(a) Consider an individual with the expected utility preferences in (3) and (4), for which future utility does not depend on past consumption. The payoffs of any monetary gambles she is offered are assumed not to affect, and to be independent of, $I_{t}$ and future economic uncertainty. Suppose that for given $I_{t}$, she rejects $G_{S}$ at wealth levels below \$1,000,000. Then she also rejects $G_{L}$ at wealth levels below $\$ 1,000,000$.

(b) Consider an individual with the expected utility preferences in (3) and (5), for which future utility does depend on past consumption. The payoffs of any monetary gambles she is offered are assumed not to affect, and to be independent of, $I_{t}$ and future economic uncertainty. Suppose that for given $I_{t}$ and $C_{-t}$, she rejects $G_{S}$ at wealth levels below \$1,000,000. Then she also rejects $G_{L}$ at wealth levels below $\$ 1,000,000$.

Proof: See the Appendix. 
In words, the proposition says that any expected utility function able to explain observation I - the rejection of $G_{S}$, the $550 / 500$ bet - will inevitably fail to explain observation II, the acceptance of $G_{L}$, the 20 million/10, 000 bet.

The proposition covers a wide range of utility specifications, including most of those used by financial economists. Part (a) of the proposition covers time-separable and stateindependent utility of the form

$$
U\left(C_{0}, \ldots, C_{T}\right)=\sum_{t=0}^{T} u_{t}\left(C_{t}\right),
$$

but also allows for state-dependence, such as external habit dependence (Abel 1990, Campbell and Cochrane 1999). Part (b) addresses non-time-separable preferences, including those with internal habit dependence (Sundaresan 1989, Constantinides 1990).

Proposition 1 can be thought of as an intertemporal generalization of Rabin (2000), who shows that in a static one-period setting, no EU specification with an increasing, concave utility function defined over wealth can explain both observations I and II. The intuition for Rabin's finding, and hence also for Proposition 1, is straightforward. An individual with the EU preferences in (3) is locally risk-neutral; since gamble $G_{S}$ involves small stakes, she would normally take it without hesitating. To get her to reject it, in accordance with observation I, we need to make her locally risk averse. In fact, her utility function must be locally risk averse at all wealth levels below $\$ 1,000,000$, because observation I requires rejection of $G_{S}$ at all points in that range. Proposition 1 simply states that "linking together" all these locally concave pieces gives a utility function with a level of global risk aversion so high that the agent rejects even the very favorable large gamble $G_{L}$.

At first sight, it might seem from Proposition 1 that Rabin's (2000) argument transfers easily to the intertemporal setting. However, this is not completely true. The argument works much better for certain types of utility functions than for others. As is reasonable in a one-period context, Rabin (2000) considers utility functions that are defined over wealth alone. In an intertemporal setting, value functions often depend not only on wealth but also, as shown in (4) and (5), on state variables $I_{t}$ and past consumption $C_{-t}$. To apply Rabin's argument, then, we need the assumption given in each part of the proposition, namely that keeping these other variables fixed, $G_{S}$ is rejected over a range of wealth levels.

The difficulty is that this assumption may be hard to verify. Consider an individual with internal habit preferences, covered in part (b) of the proposition. There, we assume that for fixed $C_{-t}$, the investor rejects $G_{S}$ over a range of wealth levels. To provide evidence that this assumption is reasonable, we could ask people with different wealth levels, but the same past consumption, about their attitudes to $G_{S}$. The problem is now clear: it is hard to find a group of subjects to do this experiment with, because people with different wealth levels tend to have different past consumption. This caveat does not let habit-based preferences 
off the hook though, because they are still subject to more general criticisms that we make later of all utility functions displaying second-order risk aversion, whether expected utility or non-expected utility. ${ }^{11}$

Initial indications of the problem with EU preferences appear in Kandel and Stambaugh (1991), who show that in a one-period setting, power utility preferences

$$
U(W)=\frac{W^{1-\gamma}}{1-\gamma}
$$

have trouble simultaneously capturing attitudes to both small- and large-scale risks. Whatever value of $\gamma$ is chosen, Kandel and Stambaugh (1991) show that the resulting preferences make counterintuitive predictions either about large-scale or about small-scale gambles. Rabin (2000) and Proposition 1 above show that this problem arises not only for power utility functions but for all expected utility specifications. When they are calibrated to fit attitudes to small-scale gambles, they are unable to fit attitudes to large-scale gambles.

\section{$3.2 \quad$ Non-expected Utility}

Having shown that EU preferences are unable to explain observations I and II, we turn to non-expected utility specifications.

\section{Recursive utility with expected utility certainty equivalent [R-EU]}

We begin with the following proposition, which shows that the first type of non-EU preferences, R-EU, cannot explain observations I and II.

Proposition 2. Consider an individual with the recursive preferences in (1), where $\mu$ has the expected utility form in (2) for some increasing, concave $h$, so that the value function is

$$
J\left(W_{t} ; I_{t}\right)=\max W\left(C_{t}, \mu\left(\widetilde{V}_{t+1} \mid I_{t}\right)\right) .
$$

The payoffs of any monetary gambles she is offered are assumed not to affect, and to be independent of, $I_{t}$ and future economic uncertainty. Suppose that for given $I_{t}$, she rejects $G_{S}$ at wealth levels below $\$ 1,000,000$. Then she also rejects $G_{L}$ at wealth levels below $\$ 1,000,000$.

\footnotetext{
${ }^{11}$ Rubinstein (2001) points out that Rabin's (2000) argument applies only when utility is defined over wealth, not when it is defined over wealth changes. This critique is not relevant to our specific analysis. Financial economists define utility over consumption streams and as noted in the main text, such utility functions lead quite generally to value functions defined over wealth, not changes in wealth. However, there is a sense in which the difficulty that arises when applying Proposition 1 to internal habit preferences is similar to the difficulty noted by Rubinstein (2001). In the case of internal habit, the value function $J\left(W_{t} ; I_{t}, C_{-t}\right)$ comes close to being a function of wealth changes, since past consumption $C_{-t}$ is likely to be closely related to past wealth.
} 
Proof: See the Appendix.

In words, the proposition says that if an R-EU preference specification is calibrated to match observation I - the rejection of $G_{S}$, the $550 / 500$ bet - it then fails to match observation II, in that it predicts the rejection of $G_{L}$, the 20 million/10, 000 bet.

In proving the proposition, we have to take a stand on how an investor with the recursive preferences in (1) evaluates immediate gambles. We simply adopt the method suggested by Epstein and Zin (1989), who lay out a careful exposition of recursive utility. They propose that in order to evaluate an immediate gamble $\widetilde{v}$, the agent inserts an infinitesimal time step $\Delta t$ at time $t$, immediately before time $t$ consumption $C_{t}$ is chosen, and then applies the recursive utility calculation over this time step, checking whether the utility from taking the gamble,

$$
W\left(0, \mu\left(\widetilde{V}_{t+\Delta t}\right)\right)=W\left(0, \mu\left(J\left(\widetilde{W}_{t+\Delta t}\right)\right)\right)=W\left(0, \mu\left(J\left(W_{t}+\widetilde{v}\right)\right)\right),
$$

is greater than the utility from not taking the gamble,

$$
W\left(0, \mu\left(V_{t+\Delta t}\right)\right)=W\left(0, \mu\left(J\left(W_{t+\Delta t}\right)\right)\right)=W\left(0, \mu\left(J\left(W_{t}\right)\right)\right) .
$$

The decision therefore comes down to comparing $\mu\left(J\left(W_{t}+\widetilde{v}\right)\right)$ and $\mu\left(J\left(W_{t}\right)\right)$.

The idea behind the proof is now easy to see. Since

$$
\mu(J(\cdot))=h^{-1} E(h(J(\cdot)))
$$

attitudes to risk are determined by the expected utility function $E(h(J(\cdot)))$, even if the preferences in Proposition 2 are non-expected utility. Therefore, just as expected utility functions cannot explain observations I and II - our result in Proposition 1 - so recursive utility with an expected utility functional $\mu$ cannot explain them either.

\section{Recursive utility with second-order risk averse certainty equivalent [R-SORA]}

We now turn to the second kind of non-EU preference, R-SORA: recursive utility with a certainty equivalent function $\mu$ that is non-EU, but still second-order risk averse. In this case, it is impossible to prove that such preferences can never explain observations I and II. In particular, the Rabin (2000) argument cannot be applied as before. That argument hinges on a property of the EU preferences in (4) and (5), namely that the utility difference between two wealth levels does not depend on current wealth: the increase in utility from having $\$ 21,000$ rather than $\$ 20,000$ is the same, whether current wealth is $\$ 10,000$ or $\$ 20,000$. This property is useful because it means that attitudes to small risks at one wealth level provide valuable information about attitudes to larger risks at other wealth levels: knowing that someone turns down a small gamble like $G_{S}$ at a wealth level of $\$ 20,000$ tells us something about how, at a wealth level of $\$ 10,000$, she would react to a large risk like 
$G_{L}$ that might bring her into the neighborhood of $\$ 20,000$. Without this property of EU preferences, it is harder to put restrictions on attitudes to large-scale risks based solely on attitudes to small-scale risks.

While R-SORA preferences can, in principle, explain observations I and II, we argue that it is still not at all easy for them to do so. An investor with these preferences is locally risk-neutral and so will normally be happy to accept a small, actuarially fair gamble like $G_{S}$. To make her reject it, R-SORA preferences need to generate very high local curvature, which in turn means choosing very extreme parameters. However, such parameters almost always also imply high global risk aversion, thereby making the individual reject apparently attractive larger-scale gambles like $G_{L}$.

We illustrate this difficulty by considering a simple example of a utility function in the R-SORA class:

$$
W(C, \mu)=\left((1-\beta) C^{\rho}+\beta \mu^{\rho}\right)^{\frac{1}{\rho}}, \rho<1, \rho \neq 0,
$$

where $\mu$ takes a form suggested by Chew and MacCrimmon (1979) and Chew (1983), namely "weighted utility":

$$
\mu(\tilde{V})=\left(\frac{E\left(\tilde{V}^{1-\gamma+\delta}\right)}{E\left(\tilde{V}^{\delta}\right)}\right)^{1 /(1-\gamma)}, \gamma \neq 1 .
$$

Risk aversion increases as $\gamma$ increases or as $\delta$ falls. When $\delta=0, \mu(\cdot)$ reduces to the standard power utility form.

Epstein and Zin (1989) show that when investment opportunities are i.i.d., the individual's value function is given by

$$
J\left(W_{t}\right)=\Gamma W_{t}
$$

for some constant $\Gamma$. Substituting this value function into expressions (8) and (9), we see that the agent accepts a gamble $\widetilde{v}$ iff

$$
\mu\left(W_{t}+\widetilde{v}\right)>\mu\left(W_{t}\right)
$$

Given the functional form of $\mu$ in (12), it is now easy to check the individual's attitude to an immediate gamble at any specific wealth level.

The area shaded with "+" signs in Figure 1 shows the values of $\gamma$ and $\delta$ consistent with observation I, in other words, with the investor rejecting $G_{S}$, the $550 / 500$ bet, at all wealth levels below $\$ 1,000,000$. This area is concentrated in the bottom-right of the picture because risk aversion increases as we move towards the south-east. The diagram shows, as predicted, that extreme parameters are needed to explain observation I. Over a wide range of values of $\delta, \gamma$ is in excess of 100 .

The area shaded with " $\mathrm{x}$ " signs shows the values of $\gamma$ and $\delta$ consistent with observation II, i.e., for which the investor accepts $G_{L}$, the 20 million/10, 000 bet, at all wealth levels 
above $\$ 100,000$. This region is located in the top-left corner of the picture: once risk aversion climbs too high, the investor is no longer willing to accept $G_{L}$. The figure confirms that the very high local curvature required to explain observation I often also implies high global risk aversion, thereby predicting the rejection of $G_{L}$ and violating observation II. Only a thin sliver of parameter values in the upper-right hand corner are able to explain both observations. Using a stronger restriction on large-scale risk attitudes, rather than just the relatively weak observation II, would only pose an even greater challenge for R-SORA preferences. ${ }^{12}$

\section{Recursive utility with first-order risk averse certainty equivalent [R-FORA]}

So far, we have argued that preferences exhibiting second-order risk aversion, whether expected utility or non-expected utility, fare poorly on observations I and II - indeed it is often impossible for them to explain those observations. This points to the possibility that the next class of recursive utility preferences, R-FORA, in which the certainty equivalent $\mu$ is non-expected utility and exhibits first-order risk aversion, may have more success.

In fact, as noted by Ang, Bekaert and Liu (2002) and anticipated even earlier by Epstein and Zin (1990), such preferences do indeed do a better job simultaneously explaining attitudes to small and large-scale risks. In particular, they have no trouble capturing observations I and II, so long as the gambles are played out immediately, a critical caveat we return to shortly.

The intuition for why R-FORA preferences can explain attitudes to immediate gambles is straightforward. The essence of the difficulty with EU, R-EU, and R-SORA preferences is that the investor is virtually risk-neutral to small gambles, forcing us to push risk aversion over large gambles up to dramatically high levels in order to explain the rejection of $G_{S}$, the $550 / 500$ bet. An agent with R-FORA preferences, on the other hand, is by definition locally risk averse. Risk aversion over large gambles does not, therefore, need to be increased very much to ensure that $G_{S}$ is rejected.

To see this, consider an investor with the following specific R-FORA preferences:

$$
W(C, \mu)=\left((1-\beta) C^{\rho}+\beta \mu^{\rho}\right)^{1 / \rho}, \rho<1, \rho \neq 0,
$$

where $\mu$ takes a form developed by Gul (1991),

$$
\mu(\tilde{V})^{1-\gamma}=E\left(\tilde{V}^{1-\gamma}\right)+(\lambda-1) E\left(\left(\tilde{V}^{1-\gamma}-\mu(\tilde{V})^{1-\gamma}\right) 1(\tilde{V}<\mu(\tilde{V}))\right), \gamma \neq 1 .
$$

\footnotetext{
${ }^{12}$ A slight extension of observation I also makes things harder for R-SORA preferences. People tend to reject $1.1 y / y$ and accept $4 y / y$ for a wide range of values of $y$, varying from below 20 to more than 1000 . Such "linear" behavior is very hard for R-SORA preferences to explain, as they need to invoke very strong non-linearity, or local curvature, to capture the rejection of $1.1 y / y$ for just a single value of $y$. For example, preferences discussed by Machina (1982), involving strong aversion to symmetric gambles but a preference for skewness, can capture observations I and II, but fail on this expanded version of observation I.
} 
These preferences are often referred to as "disappointment aversion" preferences: the investor gets disutility if the outcome of the gamble $\widetilde{V}$ falls below its certainty equivalent $\mu$. The parameter $\lambda$ governs the degree of disutility, in other words, how sensitive the agent is to losses as opposed to gains. Any $\lambda>1$ effectively puts a kink in the utility function at the certainty equivalent point, implying first-order risk aversion.

We now check that the utility function in (15)-(16) can easily be parameterized to explain both observations I and II for the case of immediate gambles. When investment opportunities are i.i.d., Epstein and Zin (1989) show that the investor's value function is given by

$$
J\left(W_{t}\right)=\Gamma W_{t} .
$$

Substituting this into expressions (8)-(9), we see that the investor again evaluates an immediate gamble $\widetilde{v}$ by comparing $\mu\left(W_{t}+\widetilde{v}\right)$ and $\mu\left(W_{t}\right)$. Given the functional form of $\mu$, a little algebra shows that observations I and II can be simultaneously explained if there exist $\gamma$ and $\lambda$ such that

$$
\left(\left(W_{t}+550\right)^{1-\gamma}+\lambda\left(W_{t}-500\right)^{1-\gamma}\right)^{\frac{1}{1-\gamma}}<(1+\lambda)^{\frac{1}{1-\gamma}} W_{t}
$$

holds for all wealth levels below $\$ 1,000,000$, and

$$
\left(\left(W_{t}+20,000,000\right)^{1-\gamma}+\lambda\left(W_{t}-10,000\right)^{1-\gamma}\right)^{\frac{1}{1-\gamma}}>(1+\lambda)^{\frac{1}{1-\gamma}} W_{t}
$$

holds for all wealth levels above $\$ 100,000$. A quick computation confirms that both (18) and (19) can be satisfied with $\gamma=2$ and $\lambda=2$. The intuition is that since $\lambda$ controls sensitivity to losses as opposed to gains, we need $\lambda$ to exceed 1.1 so that the $550 / 500$ bet, with its 1.1 ratio of gain to loss, is rejected.

\section{The Importance of Narrow Framing}

We now turn to our main result: that even preferences with first-order risk aversion have great difficulty explaining the simple attitudes to large and small-scale risks in observations I and II and that another ingredient, narrow framing, is also required.

This claim may seem surprising, given the example at the end of the last section, which appeared to show that preferences with first-order risk aversion can explain observations I and II. It is crucial to note, however, that those calculations are for a very special case, namely for when the monetary gambles are immediate. We now show that in the more realistic and general setting where the gambles are played out with some delay, even preferences with firstorder risk aversion have a hard time explaining observations I and II. In particular, while they can easily explain aversion to small, immediate gambles, they have great difficulty - in a sense that we make precise below - capturing aversion to small, delayed gambles. This is a serious concern because, as we saw in Section 2, people seem to be just as averse to the 
$550 / 500$ bet when it is played out immediately as when it is played out with delay. More generally, most real-world risks are delayed, making it important to get attitudes to such gambles right.

Before giving a precise statement of the difficulty with R-FORA preferences, we give a very informal example to illustrate the idea. Consider a simple one-period utility function exhibiting first-order risk aversion,

$$
w(x)=\left\{\begin{array}{lll}
x & \text { for } & x \geq 0 \\
2 x & & x<0
\end{array} .\right.
$$

It is easy for such a utility function to explain why someone might reject the small, immediate $550 / 500$ gamble: the individual would assign the gamble a value of $550\left(\frac{1}{2}\right)-2(500)\left(\frac{1}{2}\right)=$ -225 , the negative number signalling that the gamble should be rejected. But how would this individual deal with a small, delayed gamble?

In answering this, it is important to recall the essential difference between an immediate and a delayed gamble. The difference is that while waiting for the delayed gamble's uncertainty to be resolved, the individual is also likely to be exposed to other pre-existing sources of risk, such as labor income risk, house price risk, or risk from financial investments. This is not true for the immediate gamble, whose uncertainty, by definition, is resolved immediately.

For the R-FORA preferences in (15)-(16), this distinction can have a big impact on whether a gamble is accepted. Suppose that the individual is facing the pre-existing risk $\left(30,000, \frac{1}{2} ;-10,000, \frac{1}{2}\right)$, to be resolved at the end of the period, and is wondering whether to take on the independent, delayed 550/500 gamble, whose uncertainty is also to be resolved at the end of the period. The correct way for her to think about this is to merge the new gamble with the pre-existing gamble, and to check whether the combined gamble offers higher utility. Since the combined gamble is

$$
\left(30,550, \frac{1}{4} ; 29,500, \frac{1}{4} ;-9,450, \frac{1}{4} ;-10,500, \frac{1}{4}\right),
$$

the comparison is between

$$
30,000\left(\frac{1}{2}\right)-2(10,000)\left(\frac{1}{2}\right)=5000
$$

and

$$
30,550\left(\frac{1}{4}\right)+29,500\left(\frac{1}{4}\right)-2(9,450) \frac{1}{4}-2(10,500) \frac{1}{4}=5037.5 .
$$

The important point here is that the combined gamble does offer higher utility. In other words, the investor would want to accept the small, delayed gamble, even if she would reject an immediate gamble with the same stakes. The intuition is that since the investor is already facing some pre-existing risks, adding a small, independent gamble represents a form of diversification, which she enjoys, even if first-order risk averse. 
This simple example suggests that even if the certainty equivalent $\mu$ exhibits first-order risk aversion, it may be very difficult to explain the rejection of gambles like $G_{S}$, other than in the very special case where uncertainty is resolved immediately. In Proposition 3 below, we make the nature of this difficulty precise. In brief, while an individual with R-FORA utility acts in a first-order risk averse manner toward immediate gambles, she acts in a second-order risk averse manner towards independent, delayed gambles, so long as she is already facing other pre-existing risks.

This immediately reintroduces the same difficulty we saw in Section 3 when discussing preferences with second-order risk aversion. Since the agent is second-order risk averse over delayed gambles, and since the delayed gamble $G_{S}$ is small, she will normally be keen to accept it. In order to explain why it is typically rejected, we need to generate very high local curvature, which in turn means choosing very extreme parameters. However, such parameters usually also imply high global risk aversion and therefore the rejection of apparently attractive gambles with larger stakes like $G_{L}$. We illustrate this difficulty in Section 4.1 with a more formal example.

While Proposition 3 is proven for just one implementation of first-order risk aversion, the argument used in the proof is very general and can be readily applied, with minor adjustments, to other formalizations. ${ }^{13}$

Proposition 3. Consider an individual with the recursive preferences in (1), where $\mu$ has the first-order risk averse form in (16), and where $W$ is strictly increasing and twice differentiable with respect to both arguments.

Suppose that the individual is offered an actuarially favorable gamble $k \widetilde{\varepsilon}$ to pay off between time $t$ and $t+1$, and that the payoffs do not affect, and are independent of, $I_{t}$ and future economic uncertainty. Finally, suppose that prior to taking the gamble, the distribution of the agent's $t+1$ utility value $\widetilde{V}_{t+1}$ does not have finite mass at $\mu$.

Then, the individual will be second-order risk averse over the new gamble, and for sufficiently small $k$, will accept it.

Proof: See the Appendix.

An important step in the proof is an assumption about how the agent evaluates a delayed gamble $\widetilde{v}$. Epstein and Zin (1989), in their exposition of recursive preferences, do not suggest a specific methodology. We therefore adopt the most natural one, which is that the agent

\footnotetext{
${ }^{13}$ For example, by strengthening the assumption that " $\widetilde{V}_{t+1}$ does not have finite mass at $\mu$ " to " $\widetilde{V}_{t+1}$ does not have finite mass at any point," Proposition 3 can be applied when $\mu$ takes the Yaari (1987) rankdependent expected utility form, which also exhibits first-order risk aversion.
} 
merges the delayed gamble with other risks she is already taking and checks whether the combination offers higher utility. In other words, she compares the utility from not taking the gamble,

$$
W\left(C_{t}, \mu\left(\widetilde{V}_{t+1}\right)\right)=W\left(C_{t}, \mu\left(J\left(\widetilde{W}_{t+1}\right)\right)\right)=W\left(C_{t}, \mu\left(J\left(\left(W_{t}-C_{t}\right) \widetilde{R}_{t+1}\right)\right)\right),
$$

where $\widetilde{R}_{t+1}$ is the return on invested wealth between time $t$ and $t+1$, to the utility from taking it,

$$
W\left(\widehat{C}_{t}, \mu\left(\widetilde{V}_{t+1}\right)\right)=W\left(\widehat{C}_{t}, \mu\left(J\left(\widetilde{W}_{t+1}\right)\right)\right)=W\left(\widehat{C}_{t}, \mu\left(J\left(\left(W_{t}-\widehat{C}_{t}\right) \widetilde{R}_{t+1}+\widetilde{v}\right)\right)\right) .
$$

The hat over $\widehat{C}_{t}$ is a reminder that if the investor takes on the gamble, her optimal consumption choice will be different from what it is when she does not take the gamble. ${ }^{14}$

\subsection{An Example}

We now illustrate the difficulty faced by R-FORA preferences with a more formal example. In particular, we show that it is very difficult for such preferences to explain the rejection of the delayed gamble $G_{S}$ and the acceptance of the delayed gamble $G_{L}$.

To do the computations, we again consider an investor with the R-FORA preferences in (15)-(16). We assume, for simplicity, that the only investment opportunity available to the investor is a risky asset with gross return $\widetilde{R}$, where $\widetilde{R}$ has a log-normal distribution

$$
\log (\widetilde{R}) \sim N(0.04,0.03)
$$

i.i.d. over time. As before, the investor's value function takes the form

$$
J\left(W_{t}\right)=\Gamma W_{t}
$$

Substituting this into expressions (20) and (21), we see that the utility from taking a gamble $\widetilde{v}$ is:

$$
W\left(\widehat{C}_{t}, \mu\left(J\left(\left(W_{t}-\widehat{C}_{t}\right) \widetilde{R}+\widetilde{v}\right)\right)\right)=W\left(\widehat{C}_{t}, \Gamma \mu\left(\left(W_{t}-\widehat{C}_{t}\right) \widetilde{R}+\widetilde{v}\right)\right)
$$

\footnotetext{
${ }^{14}$ Strictly speaking, an agent with the preferences in (15)-(16) does not have to merge the delayed gamble with her pre-existing risk when evaluating it. Since the delayed gamble's uncertainty is resolved at a single instant in the future, she could insert an infinitesimal time interval around that future moment of resolution. Since the gamble would be her only source of wealth risk over that interval, her first-order risk aversion will lead her to reject the gamble, consistent with observation I. It is easy, however, to construct a slightly different gamble that is immune to such manipulations. Suppose that at some point in the future, the agent wins $\$ 550$ or loses $\$ 500$ with equal probability and that at each moment of time until then, the probability of eventually winning the $\$ 550$ is continuously reported. If the agent's pre-existing risk also evolves continuously over time, then an agent who cares only about overall wealth must necessarily merge the 550/500 gamble with her pre-existing risk, and therefore accepts the bet. However, we have found that in our experiments, subjects are as averse to this version of the 550/500 gamble as to the immediate and delayed versions.
} 
and the utility from not taking it,

$$
W\left(C_{t}, \mu\left(J\left(\left(W_{t}-C_{t}\right) \widetilde{R}\right)\right)\right)=W\left(C_{t}, \Gamma \mu\left(\left(W_{t}-C_{t}\right) \widetilde{R}\right)\right) .
$$

Figure 2 presents the results of comparing these two utilities. Our computations set $\beta=0.9$ and $\rho=-1$, but the results depend little on these choices. The methodology behind the calculations is described in the Appendix.

The area shaded with "+" signs shows the values of $\gamma$ and $\lambda$ for which the agent rejects the delayed 550/500 gamble. The figure shows that extreme values are required to explain this rejection, with $\gamma$ exceeding 150 across a wide range of values of $\lambda$. The intuition is that in the presence of the pre-existing risk in (22), the investor acts in a second-order risk averse manner towards delayed gambles. In order to explain the rejection of a small, delayed gamble, we need very high local curvature which, in turn, means extreme parameters.

The area marked with " $\mathrm{x}$ " signs shows the values of $\gamma$ and $\lambda$ for which the agent accepts the delayed 20 million/10, 000 gamble. Across the wide range of parameter values checked in the figure, there is no overlap at all between the two shaded regions. In other words, the figure shows that the parameters needed to explain observation I are so extreme as to also predict very high global risk aversion and thereby the rejection of apparently attractive gambles with larger stakes like $G_{L}$.

\subsection{Incorporating Narrow Framing}

So far, we have shown that two simple observations about attitudes to risk pose considerable difficulties for almost every utility specification commonly used by financial economists. What, then, can explain these observations? Clearly, first-order risk aversion is an important ingredient: we need it to explain why small gambles like $G_{S}$, played out immediately, are rejected. However, the analysis earlier in this section shows that first-order risk aversion is not enough. Its weakness is that when an agent evaluates a small, delayed gamble, she merges it with her pre-existing risks and since the resulting diversification is attractive, she happily accepts it. To explain the rejection of such a delayed gamble, then, it must be that the agent does not fully merge it with her pre-existing risks, but that to some extent, she evaluates it in isolation. More formally, she must derive utility directly from the outcome of the gamble, and not just indirectly via its contribution to total wealth, as in traditional models. Equivalently, her decision utility must depend on the outcome of the gamble over and above what that outcome implies for total wealth risk, a feature we call narrow framing. ${ }^{15}$

\footnotetext{
${ }^{15}$ Evaluating the delayed 550/500 gamble in isolation does not, strictly speaking, imply narrow framing, because the gamble's uncertainty is resolved over a single instant, over which it is the only source of wealth risk for the agent. Getting utility directly from the outcome of this gamble is therefore not necessarily "over
} 
We now check that preferences with both first-order risk aversion and narrow framing can easily explain observations I and II, whether the gambles are played out immediately or with delay. A preference specification that incorporates these two features was recently developed by Barberis and Huang (2002). In their formulation, time $t$ utility is given by

$$
V_{t}=W\left[C_{t}, \mu\left(V_{t+1}\right)+b_{0} E_{t}\left(\sum_{i} \bar{v}\left(G_{i, t+1}\right)\right)\right],
$$

where

$$
\begin{aligned}
W(C, y) & =\left((1-\beta) C^{1-\gamma}+\beta y^{1-\gamma}\right)^{1 /(1-\gamma)}, \gamma \neq 1 \\
\mu(\tilde{V}) & =\left(E\left(\tilde{V}^{1-\gamma}\right)\right)^{1 /(1-\gamma)}, \gamma \neq 1 \\
\bar{v}(x) & =\left\{\begin{array}{lll}
x & \text { for } & x \geq 0 \\
\lambda x & x<0
\end{array}\right.
\end{aligned}
$$

and where $G_{i, t+1}$ are specific gambles faced by the investor whose uncertainty will be resolved between time $t$ and $t+1$.

The term prefixed by $b_{0}$ in (26) shows that relative to the usual recursive specification in (1), we now allow utility to depend on outcomes of gambles $G_{i, t+1}$ over and above what those outcomes mean for aggregate wealth risk: $G_{i, t+1}$ now enters the utility function directly and not just indirectly via time $t+1$ utility, $V_{t+1}$. In other words, we allow for narrow framing, with the parameter $b_{0}$ controlling the degree of narrow framing: a $b_{0}$ of 0 means no narrow framing at all, while a large $b_{0}$ means that $G_{i, t+1}$ is evaluated almost completely in isolation from other risks. First-order risk aversion is also introduced, this time through the piece-wise linearity of $\bar{v}$. Indeed, since $\bar{v}$ exhibits first-order risk aversion, there is no need for $\mu(\cdot)$ to do so as well; here, $\mu(\cdot)$ simply takes a power utility form. ${ }^{16}$

Barberis and Huang (2002) propose that an agent with these preferences evaluates an immediate gamble $\widetilde{x}$ by, as before, inserting an infinitesimal time interval $\Delta t$ at time $t$, applying the recursive calculation over this time step, and checking whether the utility from taking the gamble,

$$
W\left(0, \mu\left(\widetilde{V}_{t+\Delta t}\right)+b_{0} E_{t}(\bar{v}(\widetilde{x}))\right)=W\left(0, \mu\left(J\left(W_{t}+\widetilde{x}\right)\right)+b_{0} E_{t}(\bar{v}(\widetilde{x}))\right)
$$

and above" a concern for overall wealth risk. To provide definitive evidence of narrow framing, we can use the "continuously resolved" version of the 550/500 gamble described in footnote 8. Since people are averse to that gamble as well, they must be evaluating it in isolation, to some extent. This in turn, must be narrow framing, since over the time period that the gamble's uncertainty is unfolding, it is not the only source of wealth risk to the agent. Getting utility directly from its outcome is therefore over and above any concern for overall wealth risk.

${ }^{16}$ The specification in Barberis and Huang (2002) has numerous advantages over earlier formulations that also exhibit narrow framing, like that of Barberis, Huang and Santos (2001): it allows for a more tractable partial equilibrium analysis, offers a natural way of checking attitudes to monetary gambles and does not require the scaling of individual preferences by aggregate consumption. 
is higher than the utility from not taking it,

$$
W\left(0, \mu\left(V_{t+\Delta t}\right)\right)=W\left(0, \mu\left(J\left(W_{t}\right)\right)\right) .
$$

A delayed gamble is evaluated, as before, by comparing the utility from taking it,

$$
W\left(\widehat{C}_{t}, \mu\left(\widetilde{V}_{t+1}\right)+b_{0} E_{t}(\bar{v}(\widetilde{x}))\right)=W\left(\widehat{C}_{t}, \mu\left(J\left(\left(W_{t}-\widehat{C}_{t}\right) \widetilde{R}_{t+1}+\widetilde{x}\right)\right)+b_{0} E_{t}(\bar{v}(\widetilde{x}))\right),
$$

where $\widetilde{R}_{t+1}$ is the return on invested wealth between time $t$ and $t+1$, to the utility from not taking it,

$$
W\left(C_{t}, \mu\left(\widetilde{V}_{t+1}\right)\right)=W\left(C_{t}, \mu\left(J\left(\left(W_{t}-C_{t}\right) \widetilde{R}_{t+1}\right)\right)\right),
$$

with the hat over $\widehat{C}_{t}$ again a reminder that optimal consumption changes when the gamble is accepted.

Using these expressions, we can check that the preferences in (26)-(29) do indeed explain the attitudes in observations I and II, whether the gambles are immediate or delayed. Intuitively, they should be able to do so without difficulty. Whether the 550/500 bet is immediate or delayed, the $b_{0}$ term in (26) makes the agent evaluate the gamble in isolation, to some extent. Since the $\bar{v}$ function is steeper for losses than for gains, the potential loss of $\$ 500$ looms larger than the potential gain of $\$ 550$, leading the investor to reject the gamble. In other words, if the investor's first-order risk aversion is focused specifically on the 550/500 bet rather than just on her overall wealth risk, she will be reluctant to take the bet. ${ }^{17}$

We consider the same environment as in the example of Section 4.1. The investor's only investment opportunity is a risky asset with gross return $\widetilde{R}$, distributed log-normally as

$$
\log (\widetilde{R}) \sim N(0.04,0.03)
$$

i.i.d. over time. Barberis and Huang (2002) show that in this case, the investor's value function is given by

$$
J\left(W_{t}\right)=\Gamma W_{t}
$$

Substituting this into expressions (30)-(31) and (32)-(33) allows us to determine the investor's attitudes to immediate and delayed versions of $G_{S}$ and $G_{L}$.

Figure 3 presents the results. We set $\beta$, which has little direct influence on attitudes to risk, to 0.9. More important is $b_{0}$, which controls the degree of narrow framing. We report our findings for just one value of $b_{0}$, namely 0.1 , but obtain similar results for a wide range of $b_{0}$ 's, including a $b_{0}$ as low as 0.001 . The computational methodology behind the figure is described in the Appendix.

\footnotetext{
${ }^{17}$ More formally, Barberis and Huang (2002) show that an investor with the preferences in (26)-(29) is first-order risk averse to both immediate and delayed gambles, thereby predicting rejection of a small gamble like $G_{S}$ in both cases. This is in stark contrast to the R-FORA preferences in (15)-(16) that lack narrow framing: there, the agent is first-order risk averse over immediate gambles but second-order risk averse over delayed gambles, thereby predicting rejection of the former but acceptance of the latter.
} 
The top panel in Figure 3 shows the values of $\gamma$ and $\lambda$ consistent with observation I when the gamble, $G_{S}$, is delayed, while the bottom panel shows the range of values consistent with observation II when the gamble, $G_{L}$, is also delayed. The figure shows clearly that there is a wide range of parameter values for which the preferences in (26)-(29) can explain observations I and II for delayed gambles. For example, a $\lambda$ of 3 generates enough sensitivity to losses to reject the $550 / 500$ bet, with its 1.1 gain to loss ratio, when that bet is evaluated in isolation; but it is not nearly enough sensitivity to losses to reject the highly attractive 20 million/10, 000 gamble. The figure is identical when the gambles are played out immediately.

\section{Applications}

So far, we have shown that across a wide range of utility functions, the only ones that can easily explain aversion to a small, independent, actuarially favorable gamble without making counterintuitive predictions about attitudes to large gambles, are those exhibiting both firstorder risk aversion and narrow framing. In particular, preferences with only first-order risk aversion, that do not allow for narrow framing, do not do as well. We now show that our analysis has useful implications for financial markets and specifically, for the stock market participation and equity premium puzzles.

\subsection{The Stock Market Participation Puzzle}

Consider first the participation puzzle: the fact that even though stocks have a high mean return, many people have historically appeared reluctant to allocate any money to them (Mankiw and Zeldes 1991, Haliassos and Bertaut 1995). ${ }^{18}$ One approach to this puzzle invokes transaction costs of investing in the stock market; another examines whether non-stockholders have background risk that is somewhat correlated with the stock market (Heaton and Lucas 1997, 2000, Vissing-Jorgensen, 2002). A third approach relies on heterogeneity in individual preferences, and this is the one we focus on here. In particular, we try to shed light on what kinds of preferences might most easily generate non-participation in the stock market, even when restricted to reasonable parameterizations. Following the standard practice of economists, we take a reasonable parameterization to be one that makes sensible predictions about attitudes to large gambles; for example, one that satisfies observation II, acceptance of the 20 million/10, 000 gamble at wealth levels above $\$ 100,000$.

Previous research has found that for most households, stock market risk has a correlation

\footnotetext{
${ }^{18}$ Mankiw and Zeldes (1991) report that in 1984, only $28 \%$ of households held any stock at all, and only $12 \%$ held more than $\$ 10,000$ in stock. Non-participation was not simply the result of not having any liquid assets: even among households with more than $\$ 100,000$ in liquid assets, only $48 \%$ held stocks.
} 
close to zero with other important risks, such as labor income risk, proprietary income risk and house price risk (Heaton and Lucas, 2000). Asking what kinds of preferences can explain non-participation therefore reduces to asking what kinds of preferences can explain people's refusal to add even a small amount of a relatively uncorrelated, delayed risk - stock market risk - to their other risks.

Our earlier analysis is well-suited for answering this question. There, we saw that the easiest way to explain rejection of a small, uncorrelated, delayed gamble for reasonable parameter values is to use preferences with first-order risk aversion and that allow for the narrow framing of the gamble. A simple way of explaining the rejection of a small position in the stock market for reasonable parameter values is therefore to use preferences with firstorder risk aversion and that allow for the narrow framing of stocks. This last feature means that the investor evaluates stock market risk in isolation, to some extent. More formally, her utility function depends on the outcome of any stock market gamble over and above what that outcome means for her overall wealth risk.

Our earlier analysis also makes another prediction: that preferences without narrow framing will have a harder time explaining non-participation, even if they exhibit first-order risk aversion. In the absence of narrow framing, the investor must evaluate stocks by merging them with her pre-existing risks and checking if the combination is attractive. Since stocks are a relatively uncorrelated risk, a small equity position brings useful diversification benefits which the investor generally does find attractive, even if first-order risk averse. To make such an investor withdraw from the stock market entirely, we need very high local curvature, which in turn means extreme parameters. However, such parameters almost always also imply high global risk aversion, thereby violating observation II. By having the investor evaluate stocks in isolation - by focusing her first-order risk aversion specifically on stocks rather than just on her overall wealth risk - we get around this difficulty and can more easily generate non-participation.

In making these predictions, we are assuming that results derived earlier for independent gambles will continue to hold, at least approximately, for gambles that are merely relatively uncorrelated with other risks. While this is likely to be true, the only way to be sure is to test the predictions explicitly in a simple portfolio choice setting, which is what we now do.

Consider an investor who, at the start of each period, has a fixed fraction $\bar{\theta}_{n}$ of her wealth tied up in a non-financial asset - our so-called pre-existing risk - with gross return

$$
R_{t+1}^{n}=e^{g_{n}+\sigma_{n} \varepsilon_{t+1}^{n}}
$$

and who is wondering what fraction $\theta_{s}$ of her wealth to invest in the stock market, which has gross return

$$
R_{t+1}^{s}=e^{g_{s}+\sigma_{s} \varepsilon_{t+1}^{s}}
$$


where

$$
\left(\begin{array}{l}
\varepsilon_{t}^{n} \\
\varepsilon_{t}^{s}
\end{array}\right) \sim N\left(\left(\begin{array}{l}
0 \\
0
\end{array}\right),\left(\begin{array}{ll}
1 & \omega \\
\omega & 1
\end{array}\right)\right) \text {, i.i.d. over time. }
$$

The remaining fraction of her wealth, $1-\bar{\theta}_{n}-\theta_{s}$, is to be invested in a risk-free asset earning $R_{f}$, so that the overall return on wealth is ${ }^{19}$

$$
R_{t+1}^{w}=\left(1-\bar{\theta}_{n}-\theta_{s}\right) R_{f}+\bar{\theta}_{n} R_{t+1}^{n}+\theta_{s} R_{t+1}^{s}
$$

We solve this portfolio problem for three different preference specifications: (a) as a benchmark, the power utility form

$$
\sum_{t=0}^{\infty} \beta^{t} \frac{C_{t}^{1-\gamma}}{1-\gamma}
$$

(b) preferences with first-order risk aversion and that allow for the narrow framing of stocks, which, following the formulation in (26)-(29), can be written

$$
V_{t}=W\left[C_{t}, \mu\left(\tilde{V}_{t+1}\right)+b_{0} E_{t}\left(\bar{v}\left(G_{t+1}^{s}\right)\right)\right]
$$

where $G_{t+1}^{s}$, the stock market gamble the investor is taking, is given by ${ }^{20}$

$$
G_{t+1}^{s}=\theta_{s}\left(W_{t}-C_{t}\right)\left(R_{t+1}^{s}-R_{f}\right)
$$

and finally (c), as a way of isolating the effect of narrow framing, recursive utility with first-order risk averse certainty equivalent, or R-FORA, as in (15)-(16).

The return process parameters are given in Table 2: $g_{s}$ and $\sigma_{s}$ are chosen to match historical annual data on aggregate stock returns; $g_{n}, \sigma_{n}$ and $\bar{\theta}_{n}$ are set to levels that are plausible, but our results depend little on their precise values. A more important parameter is $\omega$, the correlation between the stock market and the investor's pre-existing risks. Heaton and Lucas (2000) report correlations between the stock market and three important kinds of pre-existing risk - labor income, proprietary income and real estate - of -0.07, 0.14 and -0.2 in the aggregate, respectively. They also find that in the cross-section of households, these correlations rarely exceed 0.2 , and in their simulations, consider only correlations in the range $[-0.1,0.2]$. The $\omega$ of 0.1 assumed in Table 2 is therefore very relevant for many individual investors.

\footnotetext{
${ }^{19}$ In reality, of course, the fraction of an individual's wealth made up by a non-financial asset like a house is likely to vary over time. Fixing it at $\bar{\theta}_{n}$ is a simplifying assumption designed to keep the portfolio problem tractable, but is not crucial for our results.

${ }^{20}$ The simplest way to define the stock market gamble is $\theta_{s}\left(W_{t}-C_{t}\right)\left(R_{t+1}^{s}-1\right)$ : the capital allocated to stocks multiplied by the net return on stocks. We adopt the slight modification, proposed by Barberis, Huang and Santos (2001), of defining the gain or loss on the stock market gamble relative to the risk-free rate $R_{f}$. The logic is that a stock market return may not be considered a gain unless it is higher than the return on T-Bills.
} 
For these return process parameters, and for each utility function in turn, we compute the range of preference parameters for which the investor chooses to allocate a fraction $\theta_{s}=0$ of her overall wealth to stocks; in other words, the range of parameters for which, even though the stock market offers a high mean rate of return $-g_{s}=0.06$ - she still refuses to participate in it. We then check whether these preference parameters are reasonable, in that they satisfy observation II, acceptance of $G_{L}$. As before, we take $\beta=0.9, \rho=-1$ and $b_{0}=0.1$. In particular, we want to check that the same value of $b_{0}$ that was able to explain observations I and II in Section 4.2 can also address the participation puzzle, so that there is no need to "pick and choose" a different $b_{0}$ for each application. ${ }^{21}$

Power utility preferences illustrate the basic puzzle. For the return process parameters in Table 2, $\gamma>93$ is required to generate a $0 \%$ allocation to stocks; but for such $\gamma$, the investor would be so risk averse as to turn down a 20 million/10, 000 gamble at a wealth of $\$ 100,000$, violating observation II.

Figures 4 and 5 present results for preferences (b) and (c), respectively. In each figure, the "+" signs indicate the parameters for which the investor chooses a $0 \%$ allocation to stocks, while the "x" signs show the parameters for which she accepts $G_{L}$. Figure 4 confirms our earlier claim: as soon as narrow framing of stocks is allowed, a wide range of parameter values can deliver a low allocation to stocks, while still predicting acceptance of the 20 million/10, 000 gamble. For example, a $\lambda$ of 3 generates enough sensitivity to losses to make stocks appear unattractive when evaluated in isolation, but not nearly enough to reject $G_{L}$.

Figure 5 confirms that narrow framing plays a crucial role in this result: for the R-FORA preferences, with first-order risk aversion but no narrow framing, it is hard to produce a $0 \%$ allocation to stocks for reasonable parameter values. In fact, for this particular implementation of first-order risk aversion, it is impossible: there is no overlap at all between the two shaded regions. In the absence of narrow framing, a position in stocks is very desirable for its diversification benefits, even to a first-order risk averse investors. In this sense, the difficulties that Heaton and Lucas $(1997,2000)$ experience in trying to explain non-participation within the expected utility framework appear to carry over to much more general preference specifications.

The result in Figure 5 may be surprising, given that some authors, including Haliassos and Bertaut (1995) and Ang, Liu and Bekaert (2002), appear to show that first-order risk aversion does address the stock market participation puzzle. In fact, there is no inconsistency. Earlier research has focused on the special case where the investor has no pre-existing risk, but simply chooses between a riskless T-Bill and a risky stock market. In this case, firstorder risk aversion over total wealth risk effectively means first-order risk aversion over stock market risk, and therefore does indeed deliver a low level of stock market participation.

\footnotetext{
${ }^{21}$ For simplicity, we impose short-sales constraints and search for the optimal $\theta_{s}$ in the range $\left[0,1-\bar{\theta}_{n}\right]$. The solution technique used for each of the three preference specifications is described in the Appendix.
} 
Figure 5 shows that in the more realistic case where the investor has pre-existing risks, this result breaks down and first-order risk aversion is no longer enough. ${ }^{22}$

\subsection{The Equity Premium Puzzle}

Our analysis of monetary gambles also has useful implications for the closely related equity premium puzzle. In particular, it sheds light on the kinds of preferences that might, in a representative agent equilibrium, generate a large premium, even when restricted to reasonable parameterizations, which as before, we take to mean consistency with observation II. Specifically, our earlier results suggest that preferences with first-order risk aversion and that allow for the narrow framing of stocks will be able to generate a large premium; and that the narrow framing ingredient will again be important, in that preferences with only first-order risk aversion will not do as well.

Before giving the intuition, we demonstrate this analytically. Consider a simple endowment economy with an infinite number of identical investors, and two assets: a risk-free asset in zero net supply, with gross return $R_{f, t}$ between time $t$ and $t+1$, and a risky asset - the stock market - in fixed positive supply, with gross return $R_{t+1}$ between time $t$ and $t+1$. The stock market is a claim to a perishable stream of dividends $\left\{D_{t}\right\}$, where

$$
\frac{D_{t+1}}{D_{t}}=e^{g_{D}+\sigma_{D} \varepsilon_{t+1}}
$$

and where each period's dividend can be thought of as one component of a consumption endowment $C_{t}$, where

$$
\frac{C_{t+1}}{C_{t}}=e^{g_{C}+\sigma_{C} \eta_{t+1}}
$$

and

$$
\left(\begin{array}{l}
\varepsilon_{t} \\
\eta_{t}
\end{array}\right) \sim N\left(\left(\begin{array}{l}
0 \\
0
\end{array}\right),\left(\begin{array}{cc}
1 & \omega \\
\omega & 1
\end{array}\right)\right) \text {, i.i.d. over time. }
$$

In our quantitative analysis, we use the endowment process parameters listed in Table 3. These parameters are estimated from annual U.S. data spanning the 20th century and are standard in the literature. ${ }^{23}$

\footnotetext{
${ }^{22}$ Epstein and Schneider (2002) present a preference-based approach to the stock market participation puzzle based on aversion to ambiguity in the distribution of stock returns. This approach works in much the same way as our own, by inducing first-order risk aversion over the stock market gamble itself.

${ }^{23}$ The one exception is $\sigma_{D}$, the volatility of $\log$ dividend growth, which is approximately $12 \%$ in historical annual data but which we set to $20 \%$. Doing so does not affect the stock market Sharpe ratio generated by any of the preference specifications we consider, but it does raise the volatility of stock returns in our economy to the level observed in the data. This ensures that any inability to match the historical equity premium is not simply due to an inability to match the historical volatility of returns.
} 
We now take the same three preference specifications considered in Section 5.1., (a)-(c), and ask how large an equity premium they can generate in this simple economy, when restricted to parameters consistent with observation II. To compute equity premia, we need the Euler equations of optimality for each preference specification. For power utility preferences, the Euler equations are well-known:

$$
\begin{aligned}
1 & =\beta R_{f} E_{t}\left(\left(\frac{C_{t+1}}{C_{t}}\right)^{-\gamma}\right) \\
1 & =\beta E_{t}\left[\left(\frac{C_{t+1}}{C_{t}}\right)^{-\gamma} R_{t+1}\right] .
\end{aligned}
$$

The Euler equations for preference specification (b), derived by Barberis and Huang (2002), and for (c), derived by Epstein and Zin (1989), are given in the Appendix. As before, we take $\beta=0.9, \rho=-1$ and set the degree of narrow framing to $b_{0}=0.1 .^{24}$

Table 4 presents the results. Power utility preferences illustrate the basic puzzle: the largest premium they can generate is $0.6 \%$, corresponding to $\gamma=7$, the largest integer value of $\gamma$ consistent with observation II. The table also shows that preferences with first-order risk aversion and that allow for the narrow framing of stocks are easily able to generate very high equity premia, even when restricted to reasonable parameterizations. A $\lambda$ of 3 , for example, induces enough sensitivity to losses to make stocks appear unattractive when evaluated in isolation, thereby leading to a high premium, but not nearly enough to reject $G_{L}$. Finally the table shows that preferences with first-order risk aversion alone, that lack narrow framing, deliver substantially lower premia. $^{25}$

In light of our earlier results, none of this is surprising. In the simple representative agent economies we consider, the stock market is a relatively uncorrelated and relatively small risk. In Section 4, we saw that the preferences that can most easily explain aversion to such a risk, and thereby a large premium for holding that risk, are precisely those with first-order risk aversion and that allow for the narrow framing of the risk - in this case, the narrow framing of stocks. Moreover, preferences with first-order risk aversion alone, that lack narrow framing, are unlikely to generate as large a premium: the representative agent is then much more willing to hold stocks, as merging them with her pre-existing risks is diversifying. 26

\footnotetext{
${ }^{24}$ Benartzi and Thaler (1995) and Barberis, Huang and Santos (2001) also investigate the implications of narrow framing for the equity premium, but do not calibrate their preferences to any monetary gambles, making it hard to tell whether their parameterizations are "reasonable," in the sense of satisfying observation II.

${ }^{25}$ The table entry for narrow framing preferences reports premia of " $>6 \%$ " because we were able to obtain a premium of $6 \%$ under the restriction of observation II even after searching over only part of the parameter space.

${ }^{26}$ The reader may feel that the $3.59 \%$ equity premium generated by first-order risk averse preferences is in no way small. We agree, but note that imposing a stronger definition of "reasonable" parameters than the relatively weak observation II is likely to reduce the premium that R-FORA preferences can generate.
} 
But why can we say that in our representative agent economies, stocks are a relatively small or relatively uncorrelated gamble? Both of these features follow directly from the low correlation of consumption growth and dividend growth in Table 3. Since, in the particular economies we consider, the price-dividend and consumption-wealth ratios are constant, a low correlation between dividend growth and consumption growth implies a low correlation between stock returns and the returns on total wealth. Stocks are therefore indeed only weakly correlated with the agent's other risks, and they must also only be a small part of total wealth: if they were a large part, stock returns and returns on total wealth would be more highly correlated.

\section{Interpreting Narrow Framing}

In this paper, we have tried to argue that preferences with first-order risk aversion and that allow for narrow framing may be very useful for understanding attitudes to both independent monetary gambles and the stock market. Of these two features, narrow framing is the more unusual. It may therefore be helpful to end by suggesting some ways of interpreting it.

One way narrow framing can arise is if the agent takes non-consumption utility, such as regret, into account. Regret is the pain we feel when we realize that we would be better off today if we had taken a different action in the past. Even if a gamble that the agent accepts is just one of many risks that she faces, it is still linked to a specific decision, namely the decision to accept the gamble. As a result, it exposes the agent to possible future regret: if the gamble turns out badly, the investor may regret the decision to accept it. Consideration of non-consumption utility therefore leads quite naturally to preferences that depend on the outcomes of gambles over and above what those outcomes mean for total wealth.

A second theory of narrow framing is laid out by Kahneman (2003) in his Nobel lecture. He argues that many decisions are made intuitively, rather than through effortful reasoning. Since intuitive thoughts are by nature spontaneous, they are heavily shaped by the features of the situation at hand that come to mind most easily; to use the technical term, by the features that are most accessible. When the agent is offered a 50:50 bet to win $\$ 550$ or lose $\$ 500$, the outcomes of the gamble, $\$ 550$ and $\$ 500$, are instantly accessible; much less accessible, however, is the distribution of future outcomes the agent faces after integrating the 550/500 bet with all her other risks. Since the narrow frame is the most accessible one, it has a much greater effect on judgment.

This line of thinking has the interesting implication that if a broader frame is made

Indeed, in results not reported here but available on request, we find that if we impose the tighter restrictions on large-scale risk attitudes suggested elsewhere in the literature, the largest premium derivable from the R-FORA preferences falls to under $1 \%$. 
more accessible, perhaps by encouraging the investor to think about her overall wealth after merging the 550/500 gamble with her other holdings, she might take the bet after all. For example, a subject could be asked to think, quantitatively, about her total wealth today, $W_{0}$, and also about the distribution of her total wealth next month, $\widetilde{W}_{1}$. She would then be asked whether she would accept a bet that would give her $\widetilde{W}_{1}+550$ or $\widetilde{W}_{1}-500$ next month, with equal chance. Kahneman (2003) reports that in informal experiments, subjects are indeed less likely to reject the small gamble when coaxed into using the broader frame than when simply asked whether they would take "a 50:50 bet to win $\$ 550$ or lose $\$ 500$."

Narrow framing may also arise within firms. The manager of a particular division within a firm may, for incentive reasons, be compensated based on the division's performance. This may lead her to turn down a risky project that adds too much volatility to the division's earnings, even if the project is relatively uncorrelated with those of other divisions, and is therefore attractive from the overall firm's perspective.

In Section 5, we addressed the stock market participation and equity premium puzzles by saying that agents get utility from the outcome of their stock market investments over and above what that outcome means for their overall wealth; in other words, they frame the stock market narrowly. Does it seem plausible that narrow framing might indeed apply in the case of the stock market?

It seems to us that both the "regret" and "accessibility" interpretations of narrow framing apply naturally to decisions about the stock market. Allocating some fraction of her wealth to the stock market constitutes a concrete action on the part of the agent - one that she may later regret if her stock market gamble turns out poorly. ${ }^{27}$ Alternatively, given our daily exposure, from newspapers, books and other media, to vast amounts of information about the distribution of the stock market, such information is very accessible. Much less accessible is any information as to the distribution of future outcomes once stock risk is merged with the other kinds of risk that people often face. From this point of view, then, it is natural that judgments about how much to invest in stocks would be made, at least to some extent, using a narrow frame.

All this is not to say that people never take a broad view. In some situations, it is very possible that people exert the cognitive effort required to override their intuition-based decision-making, thereby reducing the importance of accessibility. Our claim is simply that when evaluating independent risks of small to moderate size, and for some people, when evaluating stock market risk, narrow framing does appear to play some role.

\footnotetext{
${ }^{27}$ Of course, investing in T-Bills may also lead to regret if the stock market goes up in the meantime. Regret is typically thought to be stronger, however, when it stems from having taken an action - for example, actively moving one's savings from the default option of a riskless bank account to the stock market - than from having not taken an action - for example, leaving one's savings in place at the bank. In short, errors of commission are more painful than errors of omission.
} 


\section{Conclusion}

We argue that narrow framing, whereby an agent who is offered a new gamble evaluates that gamble in isolation, separately from other risks she already faces, may be a more important feature of decision-making under risk than previously realized. To demonstrate this, we present evidence on typical attitudes to monetary gambles with both large and small stakes and show that across a wide range of utility functions, including all expected utility and many non-expected utility specifications, the only ones that can easily capture these attitudes are precisely those exhibiting narrow framing.

Of course, the fact that people appear to frame narrowly when evaluating independent laboratory gambles of small to moderate size does not prove that they also do so when evaluating real-world risks like the stock market. We show, however, that preferences that couple narrow framing of stocks with first-order risk aversion do offer attractive ways of looking at some puzzling stock market phenomena - the low historical level of stock market participation and the high historical equity premium - thereby suggesting that some people at least, may also be framing the stock market narrowly. 


\section{Appendix}

\section{Proofs of Propositions.}

Proof of Proposition 1. (We prove part (b) here. The argument for part (a) is very similar). With expected utility, and under the assumption that the outcome of a gamble does not affect $I_{t}$ and is independent of future economic uncertainty, the individual's attitude to a gamble $\widetilde{v}$ is determined by $E_{t}\left[J\left(W_{t}+\widetilde{v} ; I_{t}, C_{-t}\right)\right]$, where not taking the gamble corresponds to $\widetilde{v}=0$. The argument in Rabin (2000), which applies to one-period utility functions defined over wealth, can therefore be applied to $J\left(W_{t} ; I_{t}, C_{-t}\right)$, giving the result.

Proof of Proposition 2. Epstein and Zin (1989) propose that an individual with recursive utility preferences evaluates an immediate gamble $\widetilde{v}$ by inserting an infinitesimal time step $\Delta t$ at time $t$ and applying the recursive utility calculation over this time step. Under the assumption that the outcome of a gamble does not affect $I_{t}$ and is independent of future economic uncertainty, the individual's attitude to the gamble is determined by

$$
W\left(0, \mu\left(J\left(W_{t}+\widetilde{v} ; I_{t}\right)\right)\right)=W\left(0, h^{-1}\left[E\left(h \cdot J\left(W_{t}+\widetilde{v} ; I_{t}\right)\right)\right]\right)
$$

where not taking the gamble corresponds to $\widetilde{v}=0$. Immediate gambles are therefore again ranked by expected utility over wealth, with utility function $h \cdot J(\cdot)$. The argument in Rabin (2000), which applies to one-period utility functions defined over wealth, can therefore be applied to $h \cdot J(\cdot)$.

Proof of Proposition 3. We prove the proposition for the first-order risk averse preferences

$$
\begin{aligned}
& W(C, \mu)=\left((1-\beta) C^{\rho}+\beta \mu^{\rho}\right)^{1 / \rho} \\
& u(\mu(\tilde{V}))=E(u(\tilde{V}))+(\lambda-1) E((u(\tilde{V})-u(\mu(\tilde{V}))) 1(\tilde{V}<\mu(\tilde{V}))),
\end{aligned}
$$

where $u$ has positive first derivative and negative second derivative. When

$$
u(\widetilde{x})=E\left(\widetilde{x}^{1-\gamma}\right)^{\frac{1}{1-\gamma}}
$$

this reduces to the first-order risk averse preferences in (15)-(16).

Since $\widetilde{V}_{t+1}$ does not have finite mass at $\mu\left(\widetilde{V}_{t+1}\right)$, a small change in the period $t+1$ value function $\Delta \widetilde{V}_{t+1}=\Delta \widetilde{V}\left(\widetilde{W}_{t+1}, I_{t+1}\right)$ changes the certainty equivalent by

$$
\Delta \mu=\frac{E\left(u^{\prime}\left(\tilde{V}_{t+1}\right) \Delta \tilde{V}_{t+1}\right)+(\lambda-1) E\left(u^{\prime}\left(\tilde{V}_{t+1}\right) \Delta \tilde{V}_{t+1} 1\left(\tilde{V}_{t+1}<\mu\right)\right)}{u^{\prime}(\mu)\left(1+(\lambda-1) \operatorname{Pr}\left(V_{t+1}<\mu\right)\right)}+o\left(\left\|\Delta V_{t+1}\right\|\right)
$$

where $\mu$ denotes $\mu\left(\tilde{V}_{t+1}\right),\|x\|=E(|x|)$ and $\lim _{x \rightarrow 0}(o(x) / x)=0$, by definition. 
Assume for now that the agent does not optimally adjust her time $t$ consumption and portfolio strategy if she decides to take the gamble. Then we have

$$
\Delta \widetilde{V}_{t+1}=V_{W}\left(\widetilde{W}_{t+1}, I_{t+1}\right) \widetilde{v}+o(\|\widetilde{v}\|)
$$

which implies

$$
\Delta \mu=\frac{E\left(u^{\prime}\left(\widetilde{V}_{t+1}\right) V_{W}\left(\widetilde{W}_{t+1}, I_{t+1}\right) \widetilde{v}\right)+(\lambda-1) E\left(u^{\prime}\left(\widetilde{V}_{t+1}\right) V_{W}\left(\widetilde{W}_{t+1}, I_{t+1}\right) \widetilde{v} 1\left(\widetilde{V}_{t+1}<\mu\right)\right)}{u^{\prime}(\mu)\left(1+(\lambda-1) \operatorname{Pr}\left(V_{t+1}<\mu\right)\right)}+o(\|\widetilde{v}\|) .
$$

Given that $\widetilde{v}$ is independent of other economic uncertainty, we have

$\Delta \mu=E(\widetilde{v}) \frac{E\left(u^{\prime}\left(\widetilde{V}_{t+1}\right) V_{W}\left(\widetilde{W}_{t+1}, I_{t+1}\right)\right)+(\lambda-1) E\left(u^{\prime}\left(\widetilde{V}_{t+1}\right) V_{W}\left(\widetilde{W}_{t+1}, I_{t+1}\right) 1\left(\widetilde{V}_{t+1}<\mu\right)\right)}{u^{\prime}(\mu)\left(1+(\lambda-1) \operatorname{Pr}\left(V_{t+1}<\mu\right)\right)}+o(\|\widetilde{v}\|)$,

so that to first order, the certainty equivalent value of $\widetilde{V}_{t+1}$ depends only on $E(\widetilde{v})$, not on its standard deviation.

Finally, the aggregator function $W(\cdot, \cdot)$ does not generate any first-order dependence on the standard deviation of the gamble $\widetilde{v}$. In addition, assuming that the agent adjusts her time $t$ consumption and portfolio choice optimally when accepting the gamble only introduces terms of the second order of $\widetilde{v}$.

\section{Illustrative Examples: Acceptance/Rejection of Monetary Gambles}

Recursive utility with first-order risk averse certainty equivalent

If the investor does not take the gamble, then

$$
\begin{aligned}
\Gamma W_{t} & =\max W\left(C_{t} \Gamma \mu\left(\left(W_{t}-C_{t}\right) \widetilde{R}\right)\right) \\
& =\max _{C_{t}}\left\{(1-\beta) C_{t}^{\rho}+\beta\left(W_{t}-C_{t}\right)^{\rho} \Gamma^{\rho}(\mu(\widetilde{R}))^{\rho}\right\}^{\frac{1}{\rho}} \\
& =\max _{\alpha} W_{t}\left\{(1-\beta) \alpha^{\rho}+\beta(1-\alpha)^{\rho} \Gamma^{\rho}(\mu(\widetilde{R}))^{\rho}\right\}^{\frac{1}{\rho}}
\end{aligned}
$$

where $\alpha$ is the constant fraction of wealth consumed each period by the investor. The first-order condition is

$$
(1-\beta) \alpha^{\rho-1}=\beta(1-\alpha)^{\rho-1} \Gamma^{\rho} \mu^{\rho},
$$

which, when substituted into (55), gives

$$
\Gamma=(1-\beta)^{\frac{1}{\rho}} \alpha^{\frac{\rho-1}{\rho}} .
$$

Substituting this into (56) gives

$$
\alpha=1-\beta^{\frac{1}{1-\rho}} \mu^{\frac{\rho}{1-\rho}} .
$$


Therefore, given $\mu$, which can be easily computed from its definition in (16), $\alpha$ is obtained from (58), and then $\Gamma$ from (57). This gives time $t$ utility, $\Gamma W_{t}$.

If the investor takes the gamble, utility is $\widehat{\Gamma} W_{t}$, where

$$
\widehat{\Gamma}=\max _{\alpha}\left\{(1-\beta) \alpha^{\rho}+\beta(1-\alpha)^{\rho} \Gamma^{\rho}\left(\mu\left(\widetilde{R}+\frac{\widetilde{v}}{W_{t}(1-\alpha)}\right)\right)^{\rho}\right\}^{\frac{1}{\rho}}
$$

This maximization can be performed numerically, and then $\widehat{\Gamma}$ compared to $\Gamma$ to determine if the gamble should be taken.

Recursive utility with first-order risk averse certainty equivalent and narrow framing

If the investor does not take the gamble, then

$$
\begin{aligned}
\Gamma W_{t} & =\max W\left(C_{t} \Gamma \mu\left(\left(W_{t}-C_{t}\right) \widetilde{R}\right)\right) \\
& =\max _{C_{t}}\left\{(1-\beta) C_{t}^{1-\gamma}+\beta\left(W_{t}-C_{t}\right)^{1-\gamma} \Gamma^{1-\gamma} E\left(\widetilde{R}^{1-\gamma}\right)\right\}^{\frac{1}{1-\gamma}} \\
& =\max _{\alpha} W_{t}\left\{(1-\beta) \alpha^{1-\gamma}+\beta(1-\alpha)^{1-\gamma} \Gamma^{1-\gamma} E\left(\widetilde{R}^{1-\gamma}\right)\right\}^{\frac{1}{1-\gamma}}
\end{aligned}
$$

where $\alpha$ is the constant fraction of wealth consumed each period by the investor. The first-order condition is

$$
(1-\beta) \alpha^{-\gamma}=\beta(1-\alpha)^{-\gamma} \Gamma^{1-\gamma} E\left(\widetilde{R}^{1-\gamma}\right),
$$

which, when substituted into (60), gives

$$
\Gamma=(1-\beta)^{\frac{1}{1-\gamma}} \alpha^{\frac{-\gamma}{1-\gamma}}
$$

Substituting this into (61) gives

$$
\alpha=1-\beta^{\frac{1}{\gamma}} E(\widetilde{R})^{\frac{1-\gamma}{\gamma}}
$$

Therefore, $\alpha$ is obtained from (63) and then $\Gamma$ from (62). This gives time $t$ utility, $\Gamma W_{t}$.

If the investor takes the gamble, utility is $\widehat{\Gamma} W_{t}$, where

$\widehat{\Gamma}=\max _{\alpha}\left\{(1-\beta) \alpha^{1-\gamma}+\beta(1-\alpha)^{1-\gamma}\left[\Gamma\left(E\left(\widetilde{R}+\frac{\widetilde{x}}{W_{t}(1-\alpha)}\right)^{1-\gamma}\right)^{\frac{1}{1-\gamma}}+b_{0} E\left(\bar{v}\left(\frac{\widetilde{x}}{W_{t}(1-\alpha)}\right)\right)\right]^{1-\gamma}\right\}^{\frac{1}{1-\gamma}}$

This maximization can be performed numerically, and then $\widehat{\Gamma}$ compared to $\Gamma$ to determine if the gamble should be taken.

\section{Illustrative Examples: Portfolio Choice}


Recursive utility with first-order risk averse certainty equivalent (and power utility as special case)

Epstein and Zin (1989) show that in this i.i.d. setting, the value function is $J\left(W_{t}\right)=\Gamma W_{t}$, so that the investor's problem becomes

$$
\begin{aligned}
& \max W\left(C_{t}, \Gamma \mu\left(W_{t+1}\right)\right) \\
= & \max _{\alpha, \theta_{s}}\left[(1-\beta) \alpha^{\rho}+\beta(1-\alpha)^{\rho} \Gamma^{\rho}\left(\mu\left(R_{t+1}^{W}\right)\right)^{\rho}\right]^{\frac{1}{\rho}}
\end{aligned}
$$

where $\alpha$ is the constant fraction of wealth consumed each period and where $R_{t+1}^{W}$ is defined in (39). The consumption and portfolio problems are therefore separable, with the portfolio problem given by

$$
\max _{\theta_{s}} \mu\left(R_{t+1}^{W}\right),
$$

which given the definition of $\mu$ in (16), is easily solved. Power utility preferences correspond to the special case where $\lambda=1$ and $\rho=1-\gamma$, so that the portfolio problem is given by

$$
\max _{\theta_{s}} E\left(\left(R_{t+1}^{W}\right)^{1-\gamma}\right) .
$$

Recursive utility with first-order risk averse certainty equivalent and narrow framing

Barberis and Huang (2002) show that in this i.i.d. setting, the value function is given by $J\left(W_{t}\right)=\Gamma W_{t}$, so that the investor's problem becomes

$$
\begin{aligned}
\Gamma W_{t} & =\max W\left(C_{t}, \Gamma \mu\left(W_{t+1}\right)+b_{0} E_{t}\left(\bar{v}\left(G_{t+1}^{s}\right)\right)\right) \\
& =\max _{\alpha}\left[(1-\beta) \alpha^{1-\gamma}+\beta(1-\alpha)^{1-\gamma}\left(B^{*}\right)^{1-\gamma}\right]^{\frac{1}{1-\gamma}}
\end{aligned}
$$

where $G_{t+1}^{s}$ is defined in (42) and where

$$
B^{*}=\max _{\theta_{s}} \Gamma \mu\left(R_{t+1}^{W}\right)+b_{0} \theta_{s} E_{t}\left(\bar{v}\left(R_{t+1}^{s}-R_{f}\right)\right) .
$$

The only difficulty with the portfolio problem in (69) is that it depends on the value function constant $\Gamma$. To deal with this, note that the first-order condition for consumption in $(68)$ is

$$
(1-\beta) \alpha^{-\gamma}=\beta(1-\alpha)^{-\gamma}\left(B^{*}\right)^{1-\gamma} .
$$

Substituting this into (68) gives

$$
\Gamma=(1-\beta)^{\frac{1}{1-\gamma}} \alpha^{\frac{-\gamma}{1-\gamma}} .
$$

The problem can now be solved as follows. Guess a candidate value of $\alpha$, substitute it into (71) to generate a candidate $\Gamma$, and then solve portfolio problem (69) for that $\Gamma$. Take the 
$B^{*}$ that results, substitute it into the consumption problem (68), and solve that problem to generate a new $\alpha$. Continue this iteration until convergence occurs. The converged values represent an optimum for the original problem.

\section{Illustrative Examples: Equity Premium Calculations}

Recursive utility with first-order risk averse certainty equivalent

Epstein and Zin (1989) show that the Euler equations for the R-FORA preferences are

$$
\begin{aligned}
E_{t}\left[\phi\left(\left(\frac{\beta}{1-\alpha}\right)^{1 / \rho} \frac{C_{t+1}}{C_{t}}\right)\right] & =0 \\
E_{t}\left[\phi^{\prime}\left(\left(\frac{\beta}{1-\alpha}\right)^{1 / \rho} \frac{C_{t+1}}{C_{t}}\right)\left(R_{t+1}-R_{f, t}\right)\right] & =0 \\
E_{t}\left[\phi^{\prime}\left(\left(\frac{\beta}{1-\alpha}\right)^{1 / \rho} \frac{C_{t+1}}{C_{t}}\right)\left(\frac{1}{1-\alpha} \frac{C_{t+1}}{C_{t}}-R_{f, t}\right)\right] & =0
\end{aligned}
$$

where $\alpha$ is the constant fraction of wealth consumed each period, and where

$$
\phi(x)=\left\{\begin{array}{lll}
\frac{x^{1-\gamma}-1}{1-\gamma} & \text { for } & x \geq 1 \\
\lambda \frac{x^{1-\gamma}-1}{1-\gamma} & & x<1
\end{array} .\right.
$$

Equation (72) determines $\alpha$, equation (74) determines the risk-free rate $R_{f}$ and (73) determines the expected stock return, thereby giving the equity premium.

Recursive utility with first-order risk averse certainty equivalent and narrow framing

Barberis and Huang (2002) show that the Euler equations for the narrow framing preferences are given by

$$
\begin{aligned}
\beta^{\frac{1}{1-\gamma}}(1-\alpha)^{-\frac{\gamma}{1-\gamma}} R_{f} E\left(\left(\frac{C_{t+1}}{C_{t}}\right)^{-\gamma}\right)\left(E\left(\left(\frac{C_{t+1}}{C_{t}}\right)^{1-\gamma}\right)\right)^{\frac{\gamma}{1-\gamma}} & =1 \\
\frac{E\left(\left(\frac{C_{t+1}}{C_{t}}\right)^{-\gamma}\left(R_{t+1}-R_{f}\right)\right)}{E\left(\left(\frac{C_{t+1}}{C_{t}}\right)^{-\gamma}\right)}+b_{0} R_{f}^{-1}\left(\frac{\beta}{1-\beta}\right)^{\frac{1}{1-\gamma}}\left(\frac{1-\alpha}{\alpha}\right)^{-\frac{\gamma}{1-\gamma}} E\left(\bar{v}\left(R_{t+1}-R_{f}\right)\right) & =0,
\end{aligned}
$$

where $\alpha$ is the fraction of wealth consumed by the investor. Given a risk-free rate $R_{f}, \alpha$ is obtained from (76). With $\alpha$ in hand, (77) can then be used to compute the equity premium. 


\section{References}

Abel, A. (1990), "Asset Prices Under Habit Formation and Catching Up with the Joneses," American Economic Review Papers and Proceedings 80, 38-42.

Ang, A., Bekaert G., and J. Liu (2002), "Why Stocks May Disappoint," Working paper, Columbia University.

Barberis, N. and M. Huang (2002), "A New Preference Specification that Allows for the Framing of Risks," Working paper, Stanford University.

Barberis, N., Huang M., and T. Santos (2001), "Prospect Theory and Asset Prices," Quarterly Journal of Economics 116, 1-53.

Bekaert, G., Hodrick R., and D. Marshall (1997), "The Implications of First-order Risk Aversion for Asset Market Risk Premiums," Journal of Monetary Economics 40, 3-39.

Benartzi, S. and R. Thaler (1995), "Myopic Loss Aversion and the Equity Premium Puzzle," Quarterly Journal of Economics 110, 75-92.

Campbell, J.Y. (1996), "Understanding Risk and Return," Journal of Political Economy 104, 298-345.

Campbell, J.Y. and J. Cochrane (1999), "By Force of Habit: A Consumption-based Explanation of Aggregate Stock Market Behavior," Journal of Political Economy, 107, 205-251.

Campbell, J.Y. and L. Viceira (1999), "Consumption and Portfolio Decisions when Expected Returns are Time Varying," Quarterly Journal of Economics 114, 433-495.

Chetty, R. (2002), "Consumption Commitments, Unemployment Durations and Local Risk Aversion," Working paper, Harvard University.

Chew S. (1983), "A Generalization of the Quasilinear Mean with Applications to the Measurement of Income Inequality and Decision Theory Resolving the Allais Paradox," Econometrica 51, 1065-1092.

Chew S. and K. MacCrimmon (1979), "Alpha-nu Choice Theory: An Axiomatization of Expected Utility," Working paper, University of British Columbia.

Cicchetti C. and J. Dubin (1994), "A Microeconometric Analysis of Risk Aversion and the Decision to Self-Insure," Journal of Political Economy 102, 169-186. 
Cochrane J. (1997), "Where is the Market Going? Uncertain Facts and Novel Theories," Economic Perspectives, Federal Reserve Bank of Chicago.

Constantinides, G. (1990), "Habit Formation: A Resolution of the Equity Premium Puzzle," Journal of Political Economy 98, 519-543.

Epstein, L. and M. Schneider (2002), "Learning Under Ambiguity," Working paper, University of Rochester.

Epstein, L. and S. Zin (1989), "Substitution, Risk Aversion and the Temporal Behavior of Consumption and Asset Returns: A Theoretical Perspective," Econometrica 57, 937-969.

Epstein, L. and S. Zin (1990), "First-order Risk Aversion and the Equity Premium Puzzle," Journal of Monetary Economics 26, 387-407.

Epstein, L. and S. Zin (2001), "The Independence Axiom and Asset Returns," Journal of Empirical Finance 8, 537-572.

Gneezy, U. and J. Potters (1997), “An Experiment on Risk Taking and Evaluation Periods," Quarterly Journal of Economics 112, 631-645.

Grgeta, A., and R. Thaler (2003), "Estimating Risk Aversion from the Choice of Deductibles in Automobile Insurance," Working paper, University of Chicago.

Gul, F. (1991), “A Theory of Disappointment Aversion," Econometrica 59, 667-686.

Haliassos, M. and C. Bertaut (1995), "Why Do So Few Hold Stocks?" Economic Journal 105, 1110-1129.

Heaton, J. and D. Lucas (1997), "Market Frictions, Savings Behavior and Portfolio Choice," Macroeconomic Dynamics 1, 76-101.

Heaton, J. and D. Lucas (2000), "Portfolio Choice in the Presence of Background Risk," Economic Journal 110, 1-26.

Kahneman, D. (2003), "Maps of Bounded Rationality: Psychology for Behavioral Economics," forthcoming, American Economic Review.

Kahneman, D. and D. Lovallo (1993), "Timid Choices and Bold Forecasts: A Cognitive Perspective on Risk Taking," Management Science 39, 17-31.

Kahneman, D. and A. Tversky (1979), "Prospect Theory: An Analysis of Decision under Risk," Econometrica 47, 263-291. 
Kandel, S. and R. Stambaugh (1991), "Asset Returns and Intertemporal Preferences," Journal of Monetary Economics 27, 39-71.

Machina, M. (1982), "Expected Utility Analysis without the Independence Axiom," Econometrica 50, 227-323.

Mankiw, N.G. and S. Zeldes (1991), "The Consumption of Stockholders and Non-stockholders," Journal of Financial Economics 29, 97-112.

Palacios-Huerta I., Serrano R., and O. Volij (2003), "Rejecting Small Gambles Under Expected Utility," Working paper, Brown University.

Rabin, M. (2000), "Risk Aversion and Expected Utility Theory: A Calibration Theorem," Econometrica 68, 1281-1292.

Rabin, M. and R. Thaler (2001), "Anomalies: Risk Aversion," Journal of Economic Perspectives 15, 219-232.

Read, D., Loewenstein G., and M. Rabin (1999), "Choice Bracketing," Journal of Risk and Uncertainty 19, 171-197.

Redelmeier, D. and A. Tversky (1992), "On the Framing of Multiple Prospects," Psychological Science 3, 191-193.

Rubinstein (2001), "Comments on the Risk and Time Preferences in Economics," Working paper, Princeton University.

Segal, U. and A. Spivak (1990), "First order versus Second Order Risk Aversion," Journal of Economic Theory 51, 111-125.

Sundaresan, S. (1989), "Intertemporally Dependent Preferences and the Volatility of Consumption and Wealth," Review of Financial Studies 2, 73-88.

Thaler, R., Tversky A., Kahneman D., and A. Schwartz (1997), "The Effect of Myopia and Loss Aversion on Risk Taking: An Experimental Test," Quarterly Journal of Economics $112,647-661$.

Tversky, A. and D. Kahneman (1981), "The Framing of Decisions and the Psychology of Choice," Science 211, 453-458.

Tversky, A. and D. Kahneman (1986), "Rational Choice and the Framing of Decisions," Journal of Business 59, 5251-78. 
Tversky, A., and D. Kahneman (1992), "Advances in Prospect Theory: Cumulative Representation of Uncertainty," Journal of Risk and Uncertainty 5, 297-323.

Vissing-Jorgensen, A. (2002), "Towards an Explanation of Household Portfolio Choice Heterogeneity: Nonfinancial Income and Participation Cost Structures," Working paper, Northwestern University.

Yaari, M. (1987), "The Dual Theory of Choice Under Risk," Econometrica 55, 95-115. 
Table 1: Acceptance rates for monetary gambles across five groups of subjects. Groups (i) and (v) consist of part-time MBA students at the University of Chicago, group (ii) of financial advisors at a mid-size U.S. brokerage firm, group (iii) of Chief Investment Officers and Directors of quantitative equity research at large asset management firms and group (iv) of clients of the private wealth management division of a U.S. bank. The first four gambles are immediate (their uncertainty is resolved at the time of the experiment), while the last gamble is delayed (its uncertainty is resolved a few months later). The fourth gamble listed was played for real money, while the others are hypothetical. Gamble " $\mathrm{X} / \mathrm{Y}$ " is a $50: 50$ bet to win $\$ \mathrm{X}$ or lose $\$ \mathrm{Y}$.

\begin{tabular}{llllll}
\hline & (i) & (ii) & (iii) & (iv) & (v) \\
\hline $110 / 100$ & $24 \%$ & $33 \%$ & $31 \%$ & $41 \%$ & - \\
$550 / 500\left(G_{S}\right)$ & $10 \%$ & $23 \%$ & $16 \%$ & $29 \%$ & - \\
$1,100 / 1,000$ & $4 \%$ & $20 \%$ & $5 \%$ & $15 \%$ & - \\
$110 / 100$ real money & - & - & - & - & $10 \%$ \\
$110 / 100$ delayed & - & - & - & - & $22 \%$ \\
\hline No. of subjects & 68 & 30 & 19 & 34 & 41 \\
\hline
\end{tabular}


Table 2: Parameter values for the return processes in a portfolio choice exercise: $g_{s}$ and $\sigma_{s}\left(g_{n}\right.$ and $\left.\sigma_{n}\right)$ are the mean and standard deviation of log stock market returns ( $\log$ returns on a non-financial asset); $\bar{\theta}_{n}$ is the fixed fraction of wealth held in the non-financial asset; $\omega$ is the correlation of log returns on the stock market and the non-financial asset; and $R_{f}$ is the risk-free rate.

\begin{tabular}{ll}
\hline Parameter & \\
\hline$g_{s}$ & $0.06 \%$ \\
$\sigma_{s}$ & $0.20 \%$ \\
$g_{n}$ & $0.04 \%$ \\
$\sigma_{n}$ & $0.03 \%$ \\
$\bar{\theta}_{n}$ & 0.75 \\
$\omega$ & 0.10 \\
$R_{f}$ & $1.02 \%$ \\
\hline
\end{tabular}

Table 3: Parameter values for the endowment processes in a representative agent equilibrium model: $g_{C}$ and $\sigma_{C}\left(g_{D}\right.$ and $\left.\sigma_{D}\right)$ are the mean and standard deviation of $\log$ consumption (dividend) growth; $\omega$ is the correlation of log consumption growth and log dividend growth.

\begin{tabular}{ll}
\hline Parameter & \\
\hline$g_{C}$ & $1.84 \%$ \\
$\sigma_{C}$ & $3.79 \%$ \\
$g_{D}$ & $1.5 \%$ \\
$\sigma_{D}$ & $20.0 \%$ \\
$\omega$ & 0.10 \\
\hline
\end{tabular}


Table 4: The table reports the largest equity premium that can be generated by each of three preference specifications in a simple representative agent equilibrium model, under the restriction that in equilibrium, the agent be willing to accept a $50: 50$ bet to win $\$ 20,000,000$ or lose $\$ 10,000$. The three utility functions are power utility preferences, preferences with both firstorder risk aversion and that allow for the narrow framing of stocks, and preferences with first-order risk aversion alone.

\begin{tabular}{ll}
\hline Utility & Premium \\
\hline power & $0.6 \%$ \\
narrow framing & $>6 \%$ \\
R-FORA & $3.59 \%$ \\
\hline
\end{tabular}




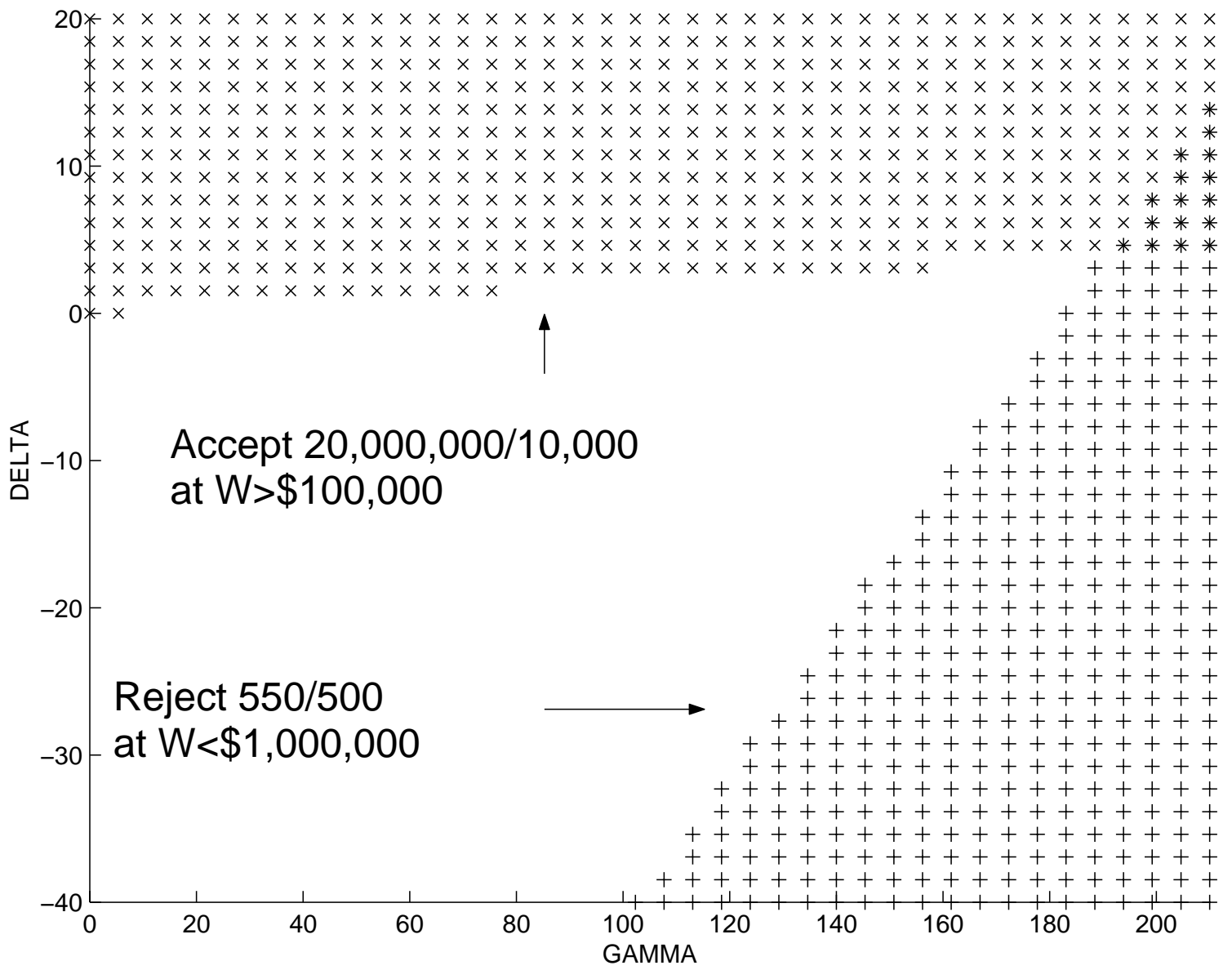

Figure 1. The "+" signs show the range of parameter values for which an agent with a recursive utility function with second-order risk averse certainty equivalent rejects a $50: 50$ bet to win $\$ 550$ or lose $\$ 500$. The " $\mathrm{x}$ " signs show the parameter values for which the agent accepts a 50:50 bet to win $\$ 20,000,000$ or lose $\$ 10,000$. 


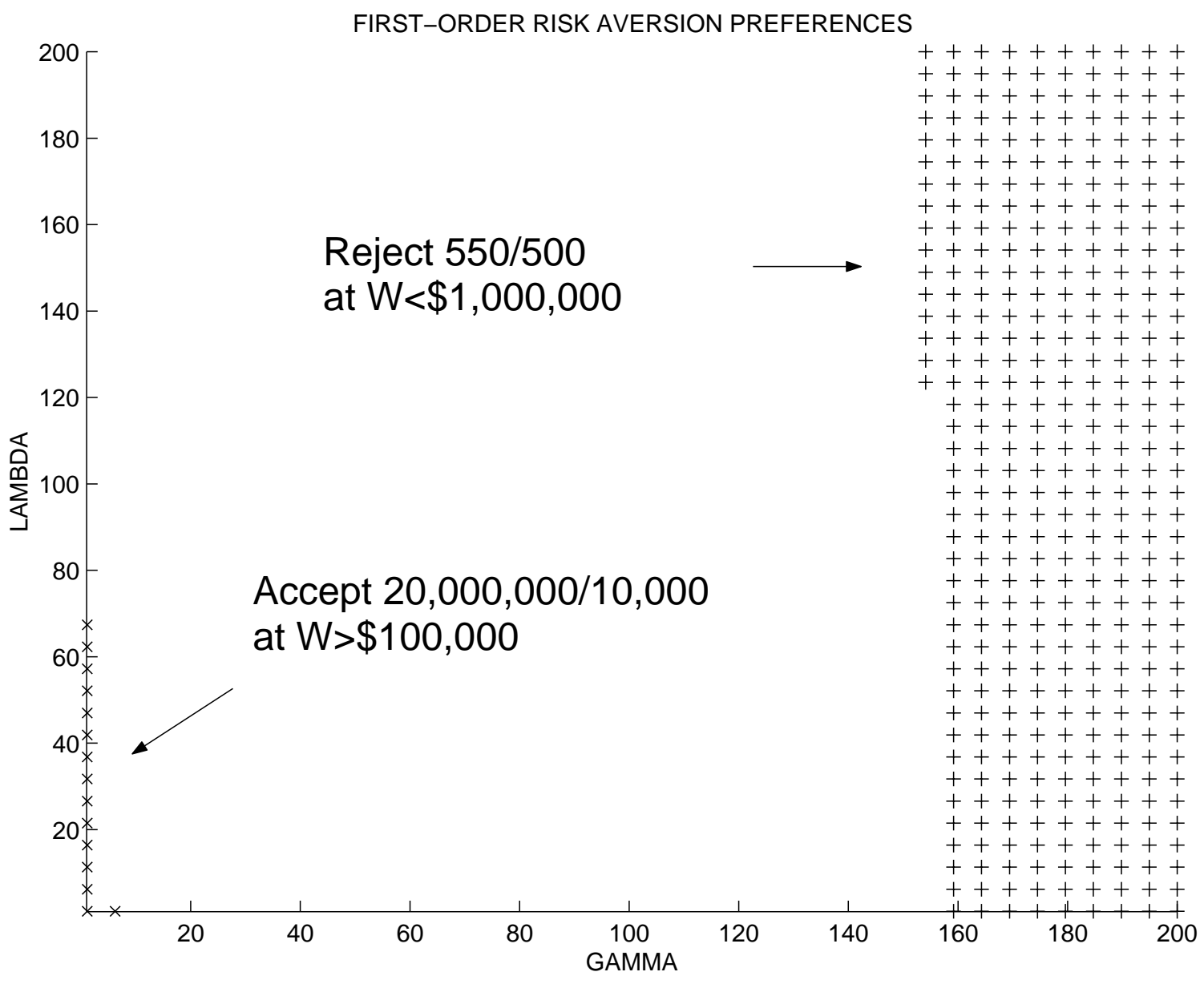

Figure 2. The "+" signs show the range of parameter values for which an agent with a recursive utility function with first-order risk averse certainty equivalent rejects a $50: 50$ bet to win $\$ 550$ or lose $\$ 500$. The "x" signs show the parameter values for which the agent accepts a $50: 50$ bet to win $\$ 20,000,000$ or lose $\$ 10,000$. 

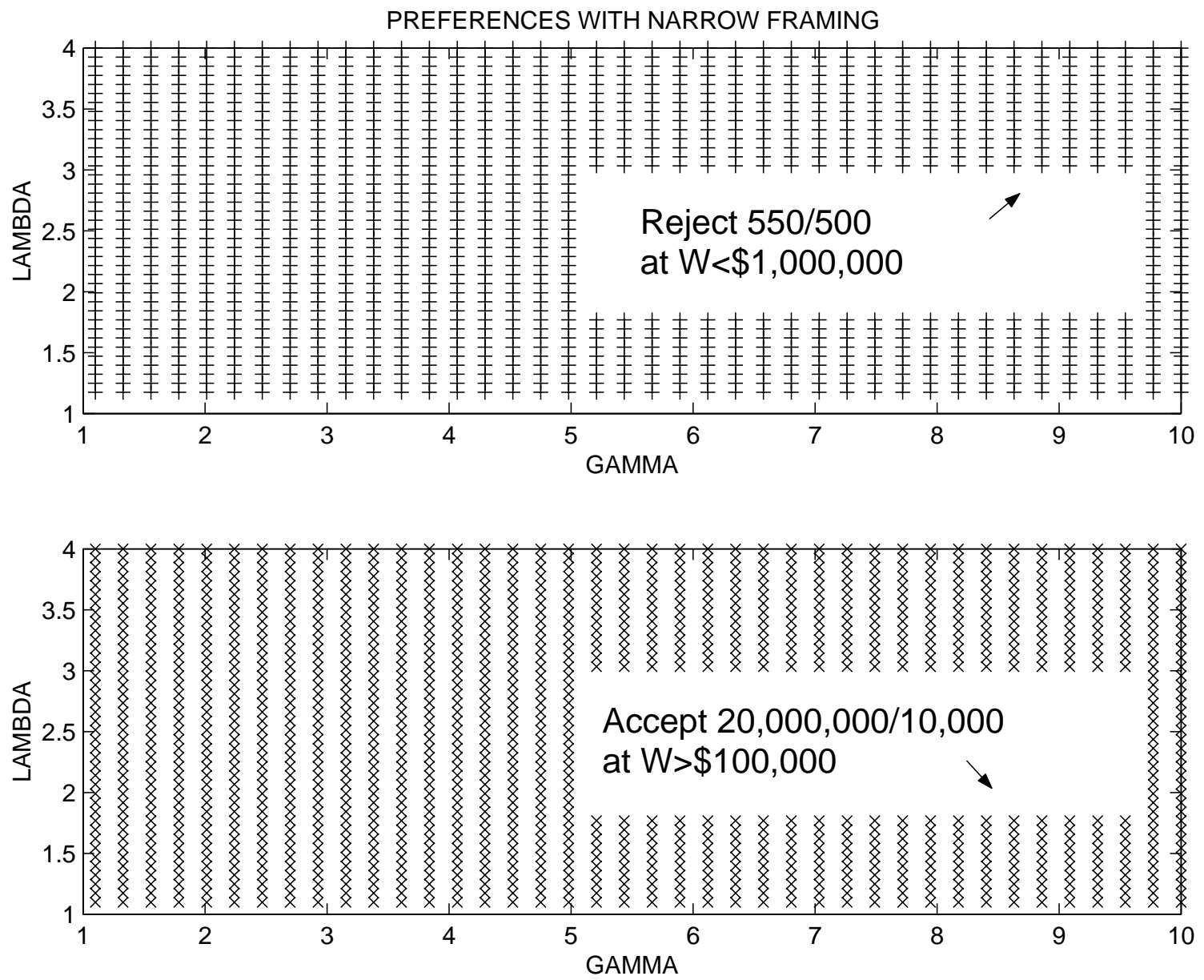

Figure 3. The "+" signs show the range of parameter values for which an agent with a recursive utility function with first-order risk averse certainty equivalent and that allows for narrow framing rejects a $50: 50$ bet to win $\$ 550$ or lose $\$ 500$. The " $x$ " signs show the parameter values for which the agent accepts a 50:50 bet to win $\$ 20,000,000$ or lose $\$ 10,000$. 

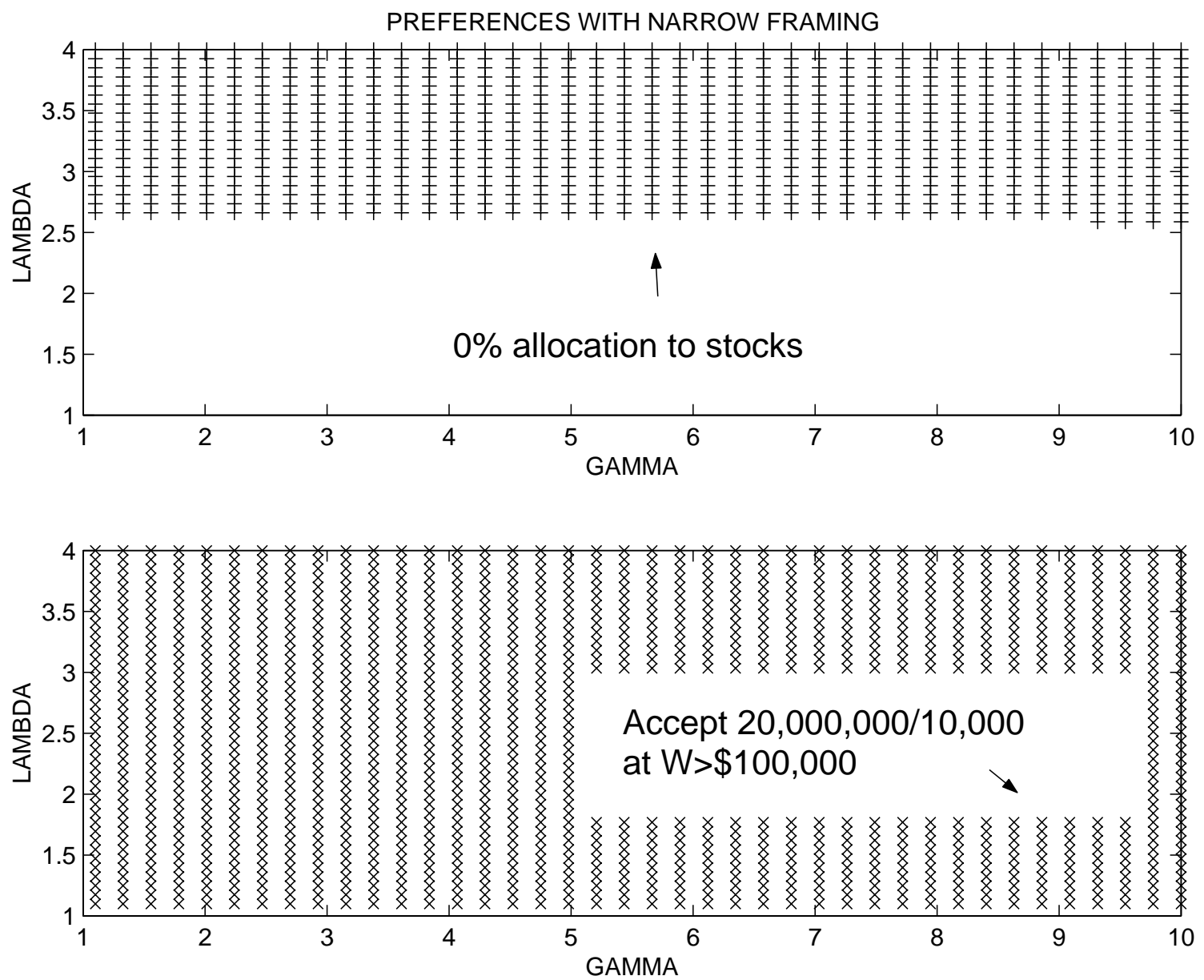

Figure 4. The "+" signs show the parameter values for which an agent with a recursive utility function with first-order risk averse certainty equivalent and that allows for narrow framing would not participate in a stock market offering a high mean return and low correlation with other risks. The " $x$ " signs show where the agent would accept a $50: 50$ bet to win $\$ 20,000,000$ or lose $\$ 10,000$. 


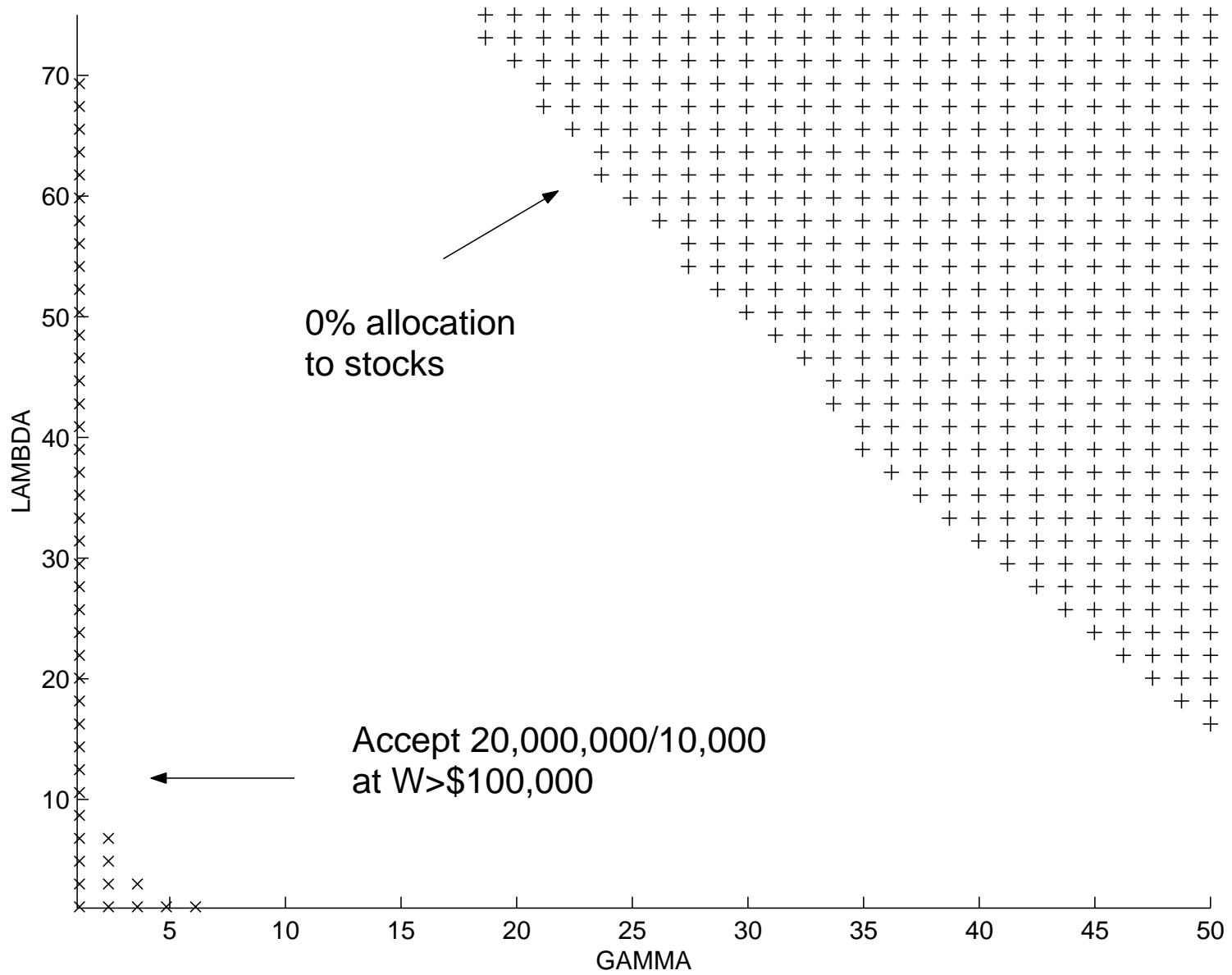

Figure 5. The "+" signs show the parameter values for which an agent with a recursive utility function with first-order risk averse certainty equivalent would not participate in a stock market offering a high mean return and low correlation with other risks. The " $\mathrm{x}$ " signs show where the agent would accept a 50:50 bet to win $\$ 20,000,000$ or lose $\$ 10,000$. 